\title{
Design of Antennas for RFID Application
}

\author{
Ming-Tao Zhang1, Yong-Chang Jiao'2, Fu-Shun Zhang² and Wu-Tu Wang ${ }^{1}$ \\ ${ }^{1}$ China Academy of Space Technology (Xi'an), Xi'an, Shaanxi, \\ ${ }^{2}$ National Laboratory of Antennas and Microwave Technology, \\ Xidian University, Xi'an, Shaanxi, \\ P. R. China
}

\section{Introduction}

As a vital and integrated part of the radio-frequency identification (RFID) system, RFID antennas have been received much attention over years, and their design is very urgent and significant. In fact, the development of RFID antenna is of theoretical significance and practical value for the RFID system. In this chapter, the RFID technology is briefly introduced, and the operating principle of the RFID system is described. The antenna in RFID system is discussed, and the designing principle of the antennas for RFID applications is presented. Some commonly used antennas in the RFID system are also displayed.

\section{RFID technology and antennas}

As an automatic identification technique without touching, RFID technology uses radio waves carrying information stored about the identified object or commands to identify object via space coupling, such as inductive coupling or electromagnetic wave propagation. For the details about the RFID technology, refer to some web sites such as www.rfidchina. org, www.rfidinfo.com.cn, www.rfidofchina.com, www.cnrfid.net, www.superrfid.net/ china/, www.rfidworld.com.cn, and www.kingant.com.

As a vital device for transmitting the RF power from the radio transceiver to the open space in the form of electromagnetic wave, or receiving it from space and transferring it to the next circuit, antenna is always the key part of the RF system, and its performance greatly affects the performance of the whole system. Thus design of antennas for the RFID system is very important. In the RFID system, according to their functions in the system, the antennas can be divided into two parts: tag antenna and reader antenna. The present RFID systems are applied at LF, HF (13.56MHz), UHF and microwave bands, and the antenna design is focused on these frequency bands. In fact, the system working at LF and HF bands is based on the magnetic field coupling between the tag coil and reader coil, whose operating principle is identical with that of the transformer. There is no radiation and wave transmission, and the antenna in the system is just a coil. The antenna discussed here is limited to the system that operates at UHF band, or microwave bands. Based on the different operating principles at different bands, design of the antennas in the system will be discussed at following sections. 


\subsection{Antennas in the RFID system}

According to the different functions in the RFID system, the RFID antennas can be divided into two classes: the tag antenna and the reader antenna. The tag antenna not only transmits the wave carrying the information stored in the tag, but also needs to catch the wave from the reader to supply energy for the tag operation. Since the tag should be attached to the identified object, the size of the tag must be small enough, and the antenna should be small in size. In most cases, the tag antenna should have omnidirectional radiation or hemispherical coverage. Generally the impedance of the tag chip is not $50 \mathrm{ohm}$, and the antenna should realize the conjugate match with the tag chip directly, in order to supply the maximum power to the tag chip. In common applications, the tag antenna should be lowcost and easy to fabricate for mass production.

The reader antenna transmits the electromagnetic energy to activate or awaken the tag, realizes the data transfer and sends the instructions to the tag. Meanwhile, the reader antenna receives information from the tag. Generally the position or the orientation of the identified object is random, and the manner for attaching the tag to the identified object is unfixed. Thus the reader antenna should be a circularly polarized antenna, in order to avoid the polarization loss when the orientation of the identified object is changed. Meanwhile, the reader antenna should have low profile and realize miniaturization, some of which should operate at more than one band. In some special cases, multiple antenna technology or smart antenna arrays for beam scanning will be employed.

In passive RFID system, the energy for maintaining the tag operation comes from the electromagnetic wave transmitted by the reader antenna. Here the passive system is mainly discussed to show the impact of the antenna parameters on the system performance (Keskilammi, Sydanheimo \& Kivikoski, 2003).

To double the reading range, the transmitted power, the antenna gain, or the sensitivity of the receiver should increase at least $12 \mathrm{~dB}$. First, the impact of the antenna gain on the system performance is described. When the transmitted power is fixed, the maximum reading range of the RFID system is mainly limited by the antenna gain and the operating frequency. By the RF link analysis, the electromagnetic wave transmitted by the reader antenna radiates to the tag through the space loss, and then reversely propagates back to the reader, carrying the information stored in the tag. Suppose that the RF energy caught by the tag can be re-radiated into the space totally. Let the power transmitted by the reader be $P_{\text {transmitted }}^{\text {reader }}$, and the gain of the reader antenna be $G_{\text {reader }}$. The power density at distance $R$ where the tag is placed can be expressed as

$$
S_{1}=\frac{G_{\text {reader }} P_{\text {transmitted }}^{\text {reader }}}{4 \pi R^{2}}
$$

The power received by the tag is calculated by

$$
P_{\text {received }}^{\text {tag }}=S_{1} A_{\text {tag }}
$$

where

$$
A_{t a g}=\frac{G_{t a g} \lambda^{2}}{4 \pi}
$$


Then, we have

$$
P_{\text {received }}^{\text {tag }}=\left(\frac{\lambda}{4 \pi R}\right)^{2} G_{\text {reader }} G_{\text {tag }} P_{\text {transmitted }}^{\text {reader }} .
$$

The power density of the return wave from the tag at the position of the reader is

$$
S_{2}=\frac{G_{\text {tag }} P_{\text {received }}^{\text {tag }}}{4 \pi R^{2}}
$$

Thus the power received by the reader is

$$
P_{\text {back }}^{\text {reader }}=S_{2} A_{\text {reader }}=S_{2} G_{\text {reader }} \frac{\lambda^{2}}{4 \pi}
$$

That is

$$
P_{\text {back }}^{\text {reader }}=\left(\frac{\lambda}{4 \pi R}\right)^{4} G_{\text {reader }}^{2} G_{\text {tag }}^{2} P_{\text {transmitted }}^{\text {reader }}
$$

where $G_{\text {reader }}$ stands for the gain of the reader antenna, $A_{\text {reader }}$ the equivalent aperture of the reader antenna, $G_{t a g}$ the gain of the tag antenna, and $A_{t a g}$ the equivalent aperture of the tag antenna.

Define the equivalent transmitted power as

$$
P_{(E I R P)}=G_{\text {reader }} P_{\text {transmitted }}
$$

Then

$$
P_{\text {back }}^{\text {reader }}=\left(\frac{\lambda}{4 \pi R}\right)^{4} G_{\text {tag }}^{2} G_{\text {reader }}\left(P_{(\text {EIRP })}\right) .
$$

Denote by $P_{\text {sensitivity }}^{\text {reader }}$ the threshold power of the sensitivity. Then the maximum reading range is expressed as

$$
R=\frac{\lambda}{4 \pi} \sqrt[4]{\frac{P_{\text {transmitted }}^{\text {reader }} G_{\text {reader }}^{2} G_{\text {tag }}^{2}}{P_{\text {sensitivity }}^{\text {reader }}}}
$$

Now we analyze the RFID system by using the radar principle. Suppose that the backscattering section of the tag, including the antenna and the chip, is $\sigma^{\text {tag }}$, then the backscattering power of the tag is

$$
P_{B S}=S_{1} \sigma^{\text {tag }}=\frac{G_{\text {reader }} P_{\text {transmitted }}^{\text {reader }} \sigma^{\text {tag }}}{4 \pi R^{2}}
$$


The power density of the back scattering wave at the position of the reader is

$$
S_{2}=\frac{P_{B S}}{4 \pi R^{2}}=\frac{G_{\text {reader }} P_{\text {transmitted }}^{\text {reader }} \sigma^{\text {tag }}}{(4 \pi)^{2} R^{4}}
$$

So we have

$$
P_{\text {back }}^{\text {reader }}=S_{2} A_{\text {reader }}=S_{2} G_{\text {reader }} \frac{\lambda^{2}}{4 \pi}=\frac{P_{\text {transmitted }}^{\text {reader }} G_{\text {reader }}^{2} \sigma^{\text {tag }} \lambda^{2}}{(4 \pi)^{3} R^{4}}
$$

By adjusting the tag chip impedance according to the stored data in tag, $\sigma^{\text {tag }}$ will be changed, and then the return wave coming from the tag and received by the reader will be changed such that the amplitude modulation and demodulation can be realized. In this manner, the tag information can be read, and the object detected by the tag can be identified. Generally, the operating frequencies of the normal RFID system based on the backscattering include: $915 \mathrm{MHz}, 2.45 \mathrm{GHz}$, and $5.8 \mathrm{GHz}$, the corresponding wavelengths are $0.328 \mathrm{~m}, 0.122 \mathrm{~m}$, and $0.051 \mathrm{~m}$. Obviously, the maximum reading range is directly proportional to the wavelength. In fact, for the same distance the space loss at higher frequency is greater than that at lower frequency. The space loss $S L$ is defined as

$$
S L=\left(\frac{4 \pi R}{\lambda}\right)^{2}
$$

Commonly, the size of the antenna is relevant to its working frequency. For lower frequency, the antenna will be larger, and the size of the tag will increase. When the antenna size is fixed, the higher gain will be achieved for higher frequency. In most cases, the antenna size is a bottleneck for tag miniaturization. In order to appropriately choose the operating frequency for the RFID system, we should consider simultaneously many factors such as the space loss, the antenna gain, and the size of the tag.

There also exists another loss, called the polarization loss, which is caused by the polarization mismatch between the incoming wave and the antenna, or between the transmitting antenna and the receiving antenna. The polarization mismatch will make the antenna lose the ability to receive all the power of the wave.

Suppose $\vec{E}_{i}=\hat{\rho}_{w} E_{i}$ is the incoming wave, $\vec{E}_{a}=\hat{\rho}_{a}$ is the polarization orientation of the receiving antenna, and $\hat{\rho}_{o}$ is the vector that is orthogonal to the polarization vector of the receiving antenna. The polarization factor PLF is defined as

$$
P L F=\left|\hat{\rho}_{w} \cdot \hat{\rho}_{a}\right|^{2}=\left|\cos \varphi_{p}\right|^{2}, \text { or } P L F(d B)=10 \lg P L F
$$

Then, the power received by the antenna is denoted by

$$
P_{r}=P_{\max } \cdot P L F, \text { or } P_{r}(d B)=P_{\max }(d B)+P L F(d B)
$$


where $P_{\max }$ stands for the power of the incoming wave, or the maximum power received by the antenna when the polarizations are matched, $\hat{\rho}_{a}$ the unit polarization vector of the receiving antenna, and $\hat{\rho}_{w}$ the unit vector of the incoming wave.

Assume that the incoming wave is circularly polarized. Then the unit vector $\hat{\rho}_{w}$ can be expressed as

$$
\hat{\rho}_{w}=\frac{\sqrt{2}}{2}\left(\hat{\rho}_{a} \pm j \hat{\rho}_{o}\right)
$$

$P L F=1 / 2$, and $P L F(d B)=-3 d B$.

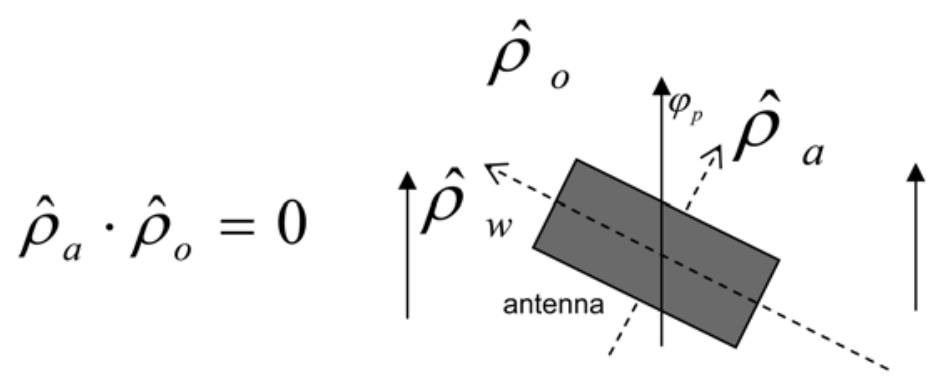

Fig. 1. Polarizations of the antenna and the wave

As shown in Fig. 1, the polarization mismatch between the antenna and the wave reduces the received power, and deteriorates the system performance. Thus choosing a suitable polarization is also an important step for designing the antenna.

\subsection{Development of antennas in the RFID system}

Potential applications of the RFID technology inspired the development of various antennas for the RFID systems. Lots of antennas with high performance for various requirements have been fabricated. As an identification system with huge market and potentials, RFID system requires the RFID antenna to meet some particular specifications. Design of the RFID antennas faces many challenges, such as the antenna structure, the antenna size, the operating mode, the bandwidth, the radiation pattern, the polarization, mutual coupling between multiple antennas, and the antenna scattering. In the present RFID system, the reader antenna is designed to be a circularly polarized antenna. Patch and spiral antennas are typical reader antennas. In some special cases, linearly polarized antennas can also be used. In the tag, the eroded or printed antennas are commonly used, and the dipole is the typical tag antenna structure. Some circularly polarized antennas for the tag may be required in some special applications.

In recent years, theory for matching the antenna with the tag chip is discussed, which guides the design of the tag antenna and the analysis of the tag configuration. Several tag antennas in common use are designed with simple impedance transformation for matching the chip with special impedance, especially for UHF band application. In the microwave band, some tag antennas are also designed to integrate with the already existing specific circuits with 50 ohm impedance. 
Schemes for designing the circularly polarized reader antenna are also presented in some literature. Based on two ports for the dual circular polarization, the aperture-coupled patch antenna integrated with the microstrip branch line coupler is preferred. Some modifications are performed to achieve the wide band, or meet the practical requirements. The system, in which multiple reader antennas are used, is also discussed.

In the design of antenna for the RFID system, some other problems, such as the environmental effects on RFID tag antennas, especially surrounded by metallic objects, should be considered. Designing the RFID tag antenna, which is mounted on the metallic objects, also faces a challenge. The inverted-F antenna and its modifications are usually used in the tag for identifying the metallic objects, and other antenna structures can also be referred in designing antenna mounted on metallic surfaces. The electromagnetic scattering of the tag antenna is also introduced and discussed, and relative calculations have been performed.

\subsection{Antenna design software for RFID application}

Efficient numerical methods promote the antenna design. Modern antenna design becomes a manipulation of accurate computing based on relative theory and a design under the theory instruction or according to the calculated results. The antenna design method based on numerical methods has been applied to design antennas for various systems. Familiar numerical methods include Method of Moment (MoM), Finite Element Method (FEM), and Finite Difference Time Domain (FDTD). There already exist several design tools based on these methods, which are of different characteristic and are widely used. Fig. 2 shows some familiar methods and the design tools. These design tools can be chosen for different problems in designing antennas. The MoM can be used to calculate the antenna performance quickly and accurately, especially for some large antenna structures. Some optimization methods, such as the optimization tool used in Zeland IE3D, can be embedded into the analysis method to make the antenna achieve the excellent performance. The FEM and FDTD methods can be used directly to analyze the antenna performance. However, the FEM method gets more accurate results than the FDTD method. The FDTD method can be used to analyze some larger antenna structures, solve the wide band problems in time domain, and give a dynamic demo about the electromagnetic field distribution and radiation. Some tools such as HFSS, which are widely used to deign antenna for the RFID system, add the ability of automatically meshing to facilitate the user and improve the precision.

These design tools should be chosen properly for designing antenna, since they have different characteristics. Some tools can be used to analyze some types of antenna suitably but lose the ability for solving other antennas or affording the large memory requirement. In designing antenna, the antenna concept based on the electromagnetic theory should be mixed with the manipulating software skilfully, and the antenna prototype of the design scheme chosen for the system requirement is more important than the skill in applying the software. After the antenna scheme is decided, being familiar with the software and the relative numerical methods will help the designer to design antenna properly, and adjust the structure parameters to optimize its performance. To succeed in designing antenna, it is of great importance to apply software under the guidance of antenna principle and electromagnetic theory. Although the function of the software for designing antenna is more powerful, the basic theory and concept is also absolutely necessary. Both the antenna theory and the design software promote the design of antennas in the RFID system. 


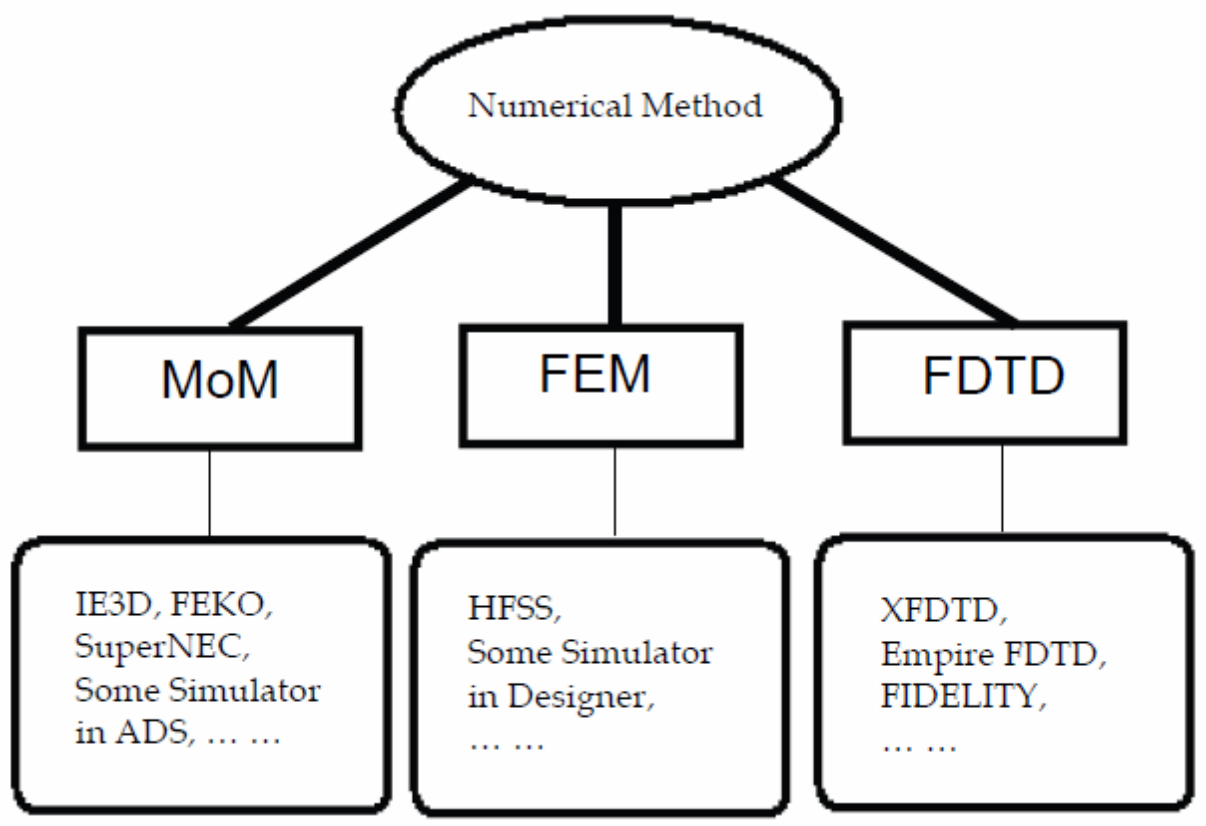

Fig. 2. Numerical methods and software

\section{Power transmission between tag chip \& antenna}

Generally, the RFID system mainly consists of reader and tag. The tag design is the most important loop in the RFID application, and also the most difficult part in the function realization. Performance of the tag usually decides the performance of the whole system. The tag is composed of the tag antenna and the chip, between which good connection and power transmission directly impact on the system configuration, the relative function realization and also the system performance. Thus, it is necessary to analyze the connection of the tag antenna to the RFID tag chip, and to discuss the impedance match problem.

\subsection{Theory of impedance match}

The most important factor in the tag is the reading range, which is the maximum distance between the reader and the tag such that the reader can detect the backscattering signal from the tag. Compared with the tag, the reader is always of high sensitivity, and the reading range is mainly limited by the performance of the tag. Especially for the passive tag, both the energy for maintaining or arousing the tag and the power of signal retransmitted by the tag are from the RF energy, which is transmitted by the reader and caught by the tag. The impedance match between the antenna and the chip has a direct influence on whether the tag circuit can operate well and the chip is able to retransmit enough energy to implement the backscattering communication, and limits the reading range.

To maximize the power transfer between the antenna and the chip, the impedance of the chip connected to the antenna should be conjugate to the antenna impedance. When the working frequency comes into the microwave band, the impedance match problem becomes 
more serious. Ordinarily, the impedance of the antenna prototype designed for the tag is 50 ohm or $75 \mathrm{ohm}$, while the chip impedance may be a random value, or vary with frequency, and have a difference when the driving power is changed. It is extremely crucial to achieve suitable impedance match between the antenna and the chip. New integrated circuit chip design and development need large investment and long research period, however, designing antenna to match the existing chip is more convenient and practical. Due to the requirements such as easy manufacture, low cost and small size, adding the matching network is infeasible. To solve this problem, the antenna should be able to match the chip directly by adjusting its structure. How to design an antenna to match a chip of arbitrary impedance is an inevitable mission in designing antenna for the RFID system (Nikitin et al., 2005; Rao, Nikitin \& Lam, 2005a).

By analyzing the tag, its equivalent circuit is shown in Fig. 3. Denote by $Z_{a}$ the antenna impedance, and $Z_{a}=R_{a}+j X_{a}$, by $Z_{c}$ the chip impedance, and $Z_{c}=R_{c}+j X_{c}$.

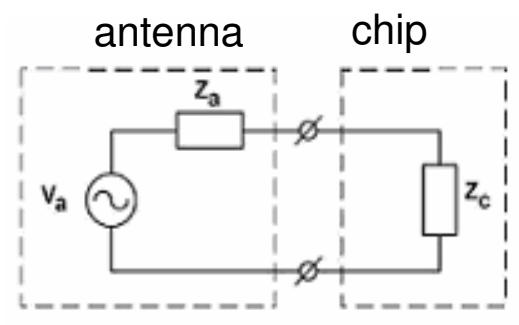

Fig. 3. Equivalent circuit of the tag

Define the complex power reflection coefficient s as

$$
s=\frac{Z_{a}-Z_{c}^{*}}{Z_{a}+Z_{c}}
$$

Then the power reflection coefficient is calculated by

$$
\begin{gathered}
|s|^{2}=\left|\frac{Z_{a}-Z_{c}^{*}}{Z_{a}+Z_{c}}\right|^{2}=\left|\frac{\left(R_{a}-R_{c}\right)+j\left(X_{a}+X_{c}\right)}{\left(R_{a}+R_{c}\right)+j\left(X_{a}+X_{c}\right)}\right|^{2} \\
=\left|\frac{\left[R_{a}+j\left(X_{a}+X_{c}\right)\right]-R_{c}}{\left[R_{a}+j\left(X_{a}+X_{c}\right)\right]+R_{c}}\right|^{2}=\left|\frac{\left(\frac{R_{a}}{R_{c}}+j \frac{X_{a}+X_{c}}{R_{c}}\right)-1}{\left.\mid \frac{R_{a}}{R_{c}}+j \frac{X_{a}+X_{c}}{R_{c}}\right)+1}\right|^{2}
\end{gathered}
$$

Let

$$
\frac{R_{a}}{R_{c}}+j \frac{X_{a}+X_{c}}{R_{c}}=r+j y=\bar{Z}_{a}
$$


be the antenna impedance normalized to the real part of the chip impedance, then

$$
|s|^{2}=\left|\frac{\bar{Z}_{a}-1}{\bar{Z}_{a}+1}\right|^{2}, \text { or }|s|=\left|\frac{\bar{Z}_{a}-1}{\bar{Z}_{a}+1}\right| \text {. }
$$

On the basis of the transformation, the traditional Smith Chart can be used to describe the impedance match between the antenna and the chip. $\bar{Z}_{a}$ can be marked according to its real part and imaginary part on Smith Chart like the traditional normalized impedance. The distance between the point of each $\bar{Z}_{a}$ and the centre point of Smith Chart expresses the magnitude of the complex power reflection coefficient $s$, while the trace of impedance points, which have a constant distance to the centre point, forms the concentric circle, which is called as the equivalent power reflection circle. The centre point of Smith Chart is the perfect impedance match point, while the most outer circle denotes the complete mismatch case, i.e. $|s|=1$.

The power transmission coefficient (Rao, Nikitin \& Lam, 2005b) can also be defined as $\tau$, and $P_{c}=P_{a} \tau$, where $P_{a}$ stands for the power from reader caught by tag antenna, $P_{c}$ the power transmitted from the tag antenna to the tag chip. It follows from Fig. 3 that

$$
\begin{gathered}
\tau=\frac{4 R_{c} R_{a}}{\left|Z_{a}+Z_{c}\right|^{2}}, 0 \leq \tau \leq 1 \\
\tau+|s|^{2}=1
\end{gathered}
$$

Let $x_{a}=\frac{X_{a}}{R_{c}}, r_{a}=\frac{R_{a}}{R_{c}}, Q_{c}=\frac{X_{c}}{R_{c}}$, then equation of the circle with constant power transmission coefficient is expressed as follows.

$$
\left[r_{a}-\left(\frac{2}{\tau}-1\right)\right]^{2}+\left[x_{a}+Q_{c}\right]^{2}=\frac{4}{\tau^{2}}(1-\tau)
$$

From equation (24), the impedance chart with the constant power transmission coefficient is draw, as shown in Fig. 4.

In Fig. 4 , the $\mathrm{x}$ axis expresses the normalized real part $r_{a}=R_{a} / R_{c}$, and $\mathrm{y}$ axis the normalized imaginary part $x_{a}=X_{a} / R_{c}$. The circles with constant power transmission coefficients $\tau=1,0.75,0.5,0.25$ are draw in Fig. 4 . The $\mathrm{x}$ axis is called as the resonant line with $X_{a}=-X_{c}$, while the $\mathrm{y}$ axis is called as the complete mismatch line. When $\tau$ 's decrease, the radius of the circles with constant power transmission coefficient increase. While $\tau \rightarrow 0$, the circle with constant power transmission coefficient approaches to its tangent, that is the $y$ axis, on which the impedance point cannot achieve the power transmission.

When the chip and the antenna are resonant, $X_{a}=-X_{c}$, and $x_{a}=-Q_{c}$, then equation (24) becomes 


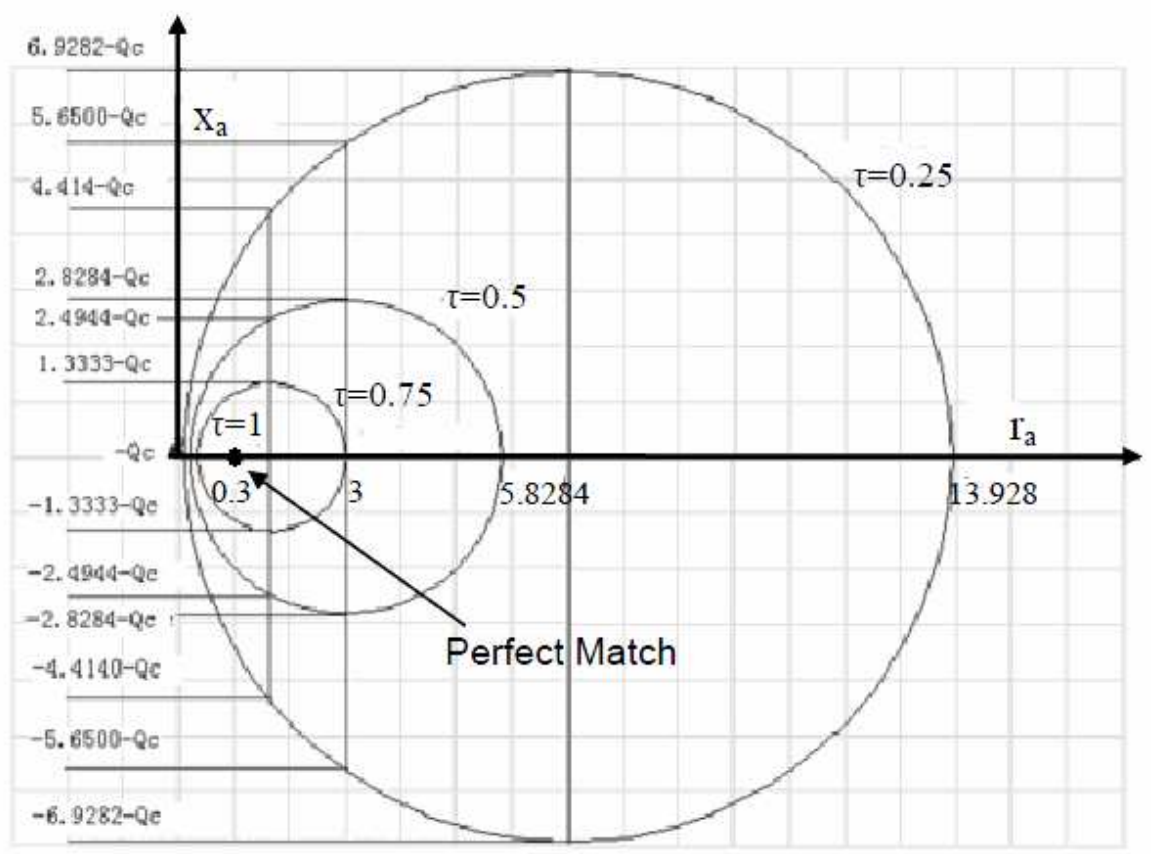

Fig. 4. The impedance chart with the constant power transmission coefficient

$$
\begin{aligned}
& {\left[r_{a}-\left(\frac{2}{\tau}-1\right)\right]^{2}=\frac{4}{\tau^{2}}(1-\tau)} \\
& {\left[\tau r_{a}-(2-\tau)\right]^{2}=4(1-\tau)}
\end{aligned}
$$

Making the derivative for the both sides of equation (26), we have

$$
\begin{gathered}
2\left[\tau r_{a}-(2-\tau)\right]\left(\tau+r_{a} \frac{d \tau}{d r_{a}}+\frac{d \tau}{d r_{a}}\right)=-4 \frac{d \tau}{d r_{a}} \\
\frac{d \tau}{d r_{a}}=\frac{\left[\left(r_{a}+1\right) \tau-2\right] \tau}{2 r_{a}}
\end{gathered}
$$

Obviously $\tau=1$ means perfect match, and $\frac{d \tau}{d r_{a}}=0 . \tau=0$ means complete mismatch, and $\frac{d \tau}{d r_{a}}=0$. Thus either the perfect match or the complete mismatch is a steady point of $\tau$ with $r_{a}$, i.e. $\frac{d \tau}{d r_{a}}=0$ 
For the fixed $\frac{R_{a}}{R_{c}}$ and $\frac{X_{a}}{X_{c}}$,

$$
\begin{gathered}
\tau=\frac{4 \frac{R_{a}}{R_{c}}}{\left|1+\frac{R_{a}}{R_{c}}+j Q_{c}\left(1+\frac{X_{a}}{X_{c}}\right)\right|}=\frac{4 \frac{R_{a}}{R_{c}}}{\left(1+\frac{R_{a}}{R_{c}}\right)^{2}+Q_{c}^{2}\left(1+\frac{X_{a}}{X_{c}}\right)^{2}} \\
\frac{d \tau}{d Q_{c}}=-8 Q_{c}\left(1+\frac{X_{a}}{X_{c}}\right)^{2} \frac{R_{a}}{R_{c}}\left[\left(1+\frac{R_{a}}{R_{c}}\right)^{2}+Q_{c}{ }^{2}\left(1+\frac{X_{a}}{X_{c}}\right)^{2}\right]^{-2}
\end{gathered}
$$

When the chip impedance is capacitive, i.e. $Q_{c}<0$, it follows from (13) that $\frac{d \tau}{d Q_{c}}>0$. While the chip impedance is inductive, i.e. $Q_{c}>0, \frac{d \tau}{d Q_{c}}<0$. When $Q_{c}=0$, i.e. $X_{c}=0$ and meanwhile $X_{a}=0$, we have

$$
\tau=\frac{4 R_{c} R_{a}}{\left(R_{c}+R_{a}\right)^{2}}
$$

The curve of $\tau$ versus $Q_{c}$ is shown in Fig.5. From this figure, we can see that for the fixed $\frac{R_{a}}{R_{c}}$ and $\frac{X_{a}}{X_{c}}, Q_{c}$ should be as small as possible from the power transmission point of view, when the tag antenna is connected to the tag chip.

For the tag antenna, the impedance chart can be used to guide the design or to describe the tag antenna. The chart is theoretically important and very useful for other applications.

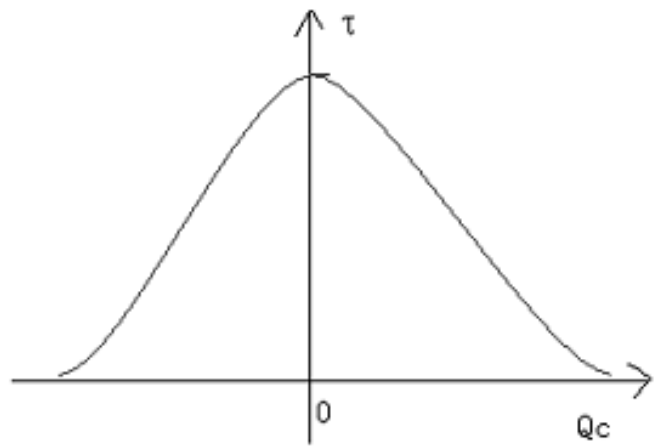

Fig. 5. Curve of $\tau$ versus $Q c$

\subsection{Impedance design for the tag antenna}

Aforementioned results indicate that the maximum power transmission can be realized only if the antenna impedance is equal to the conjugate value of the chip impedance. While the 
chip impedance is not normal $50 \mathrm{ohm}$ or $75 \mathrm{ohm}$, the structure of the tag antenna should be carefully chosen. In this section, a symmetrical inverted-F metallic strip with simple structure shown in Fig. 6 is proposed.

The antenna has the ability to realize several impedances. For UHF band application, the impedance of the antenna in four cases with different structure parameters is analyzed at $912 \mathrm{MHz}$, whose real part is approximately $22 \mathrm{ohm}, 50 \mathrm{ohm}, 75 \mathrm{ohm}, 100 \mathrm{ohm}$ respectively. The simulated results for these four cases are shown in Fig. 7.

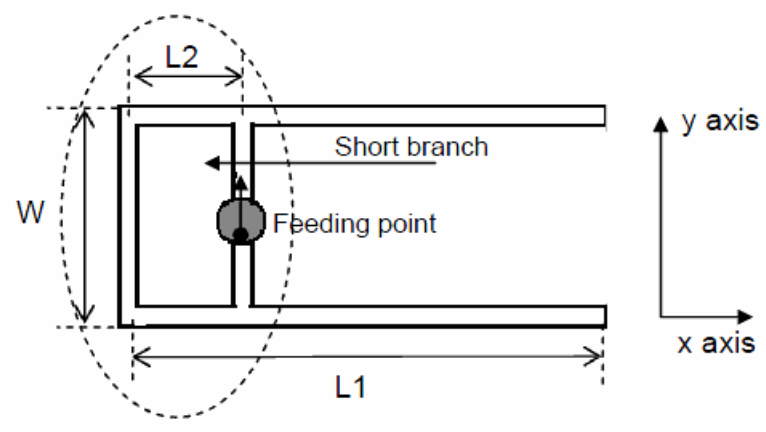

Fig. 6. The symmetrical inverted-F Antenna

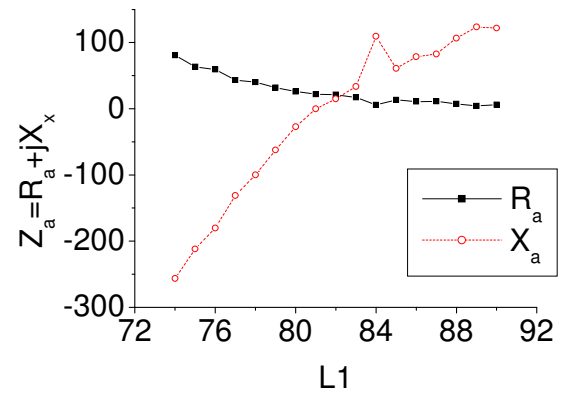

(A) $\mathrm{W}=30 \mathrm{~mm}, \mathrm{~L} 2=10 \mathrm{~mm}$

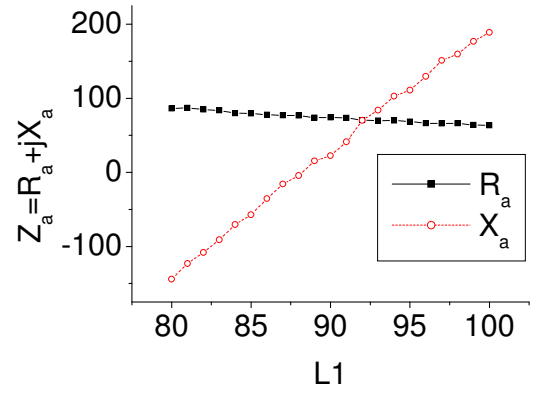

(C) $\mathrm{W}=64 \mathrm{~mm}, \mathrm{~L} 2=32 \mathrm{~mm}$

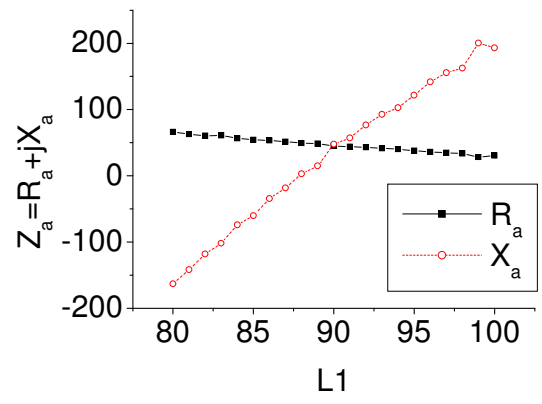

(B) $\mathrm{W}=50 \mathrm{~mm}, \mathrm{~L} 2=25 \mathrm{~mm}$

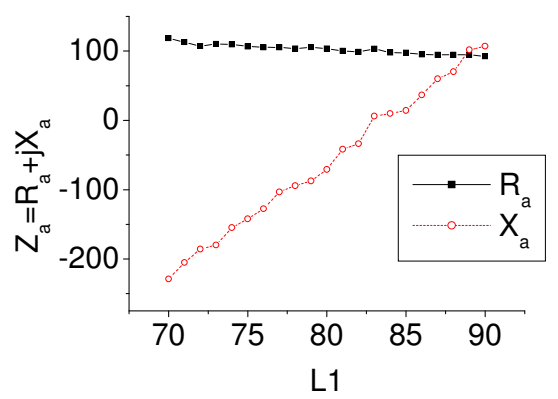

(D) $\mathrm{W}=73 \mathrm{~mm}, \mathrm{~L} 2=32 \mathrm{~mm}$

Fig. 7. Impedance results of the antenna in different cases 
Fig. 7 shows that the symmetrical inverted-F metallic strip can realize several impedance values by adjusting its short branch. A lot of familiar types of tag antennas are the modifications or transformations of this structure (Dobkin \& Weigand, 2005).

Fig. 8 shows the evolvement of several tag antennas. Antenna B has less influence on its performance than antenna A, when the antenna is curved (Tikhov \& Won, 2004). Antennas $\mathrm{C}$ and $\mathrm{D}$ are fed by an inductively coupled loop (Son \& Pyo, 2005).

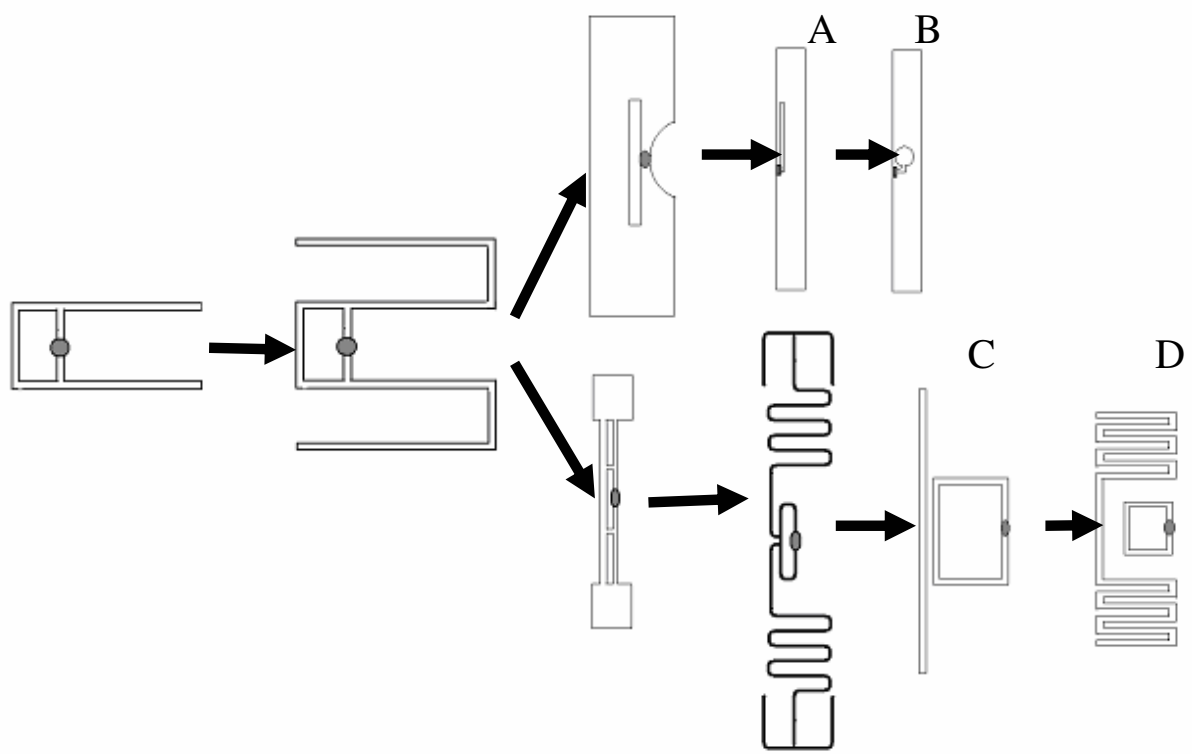

Fig. 8. Evolvement of the tag antennas

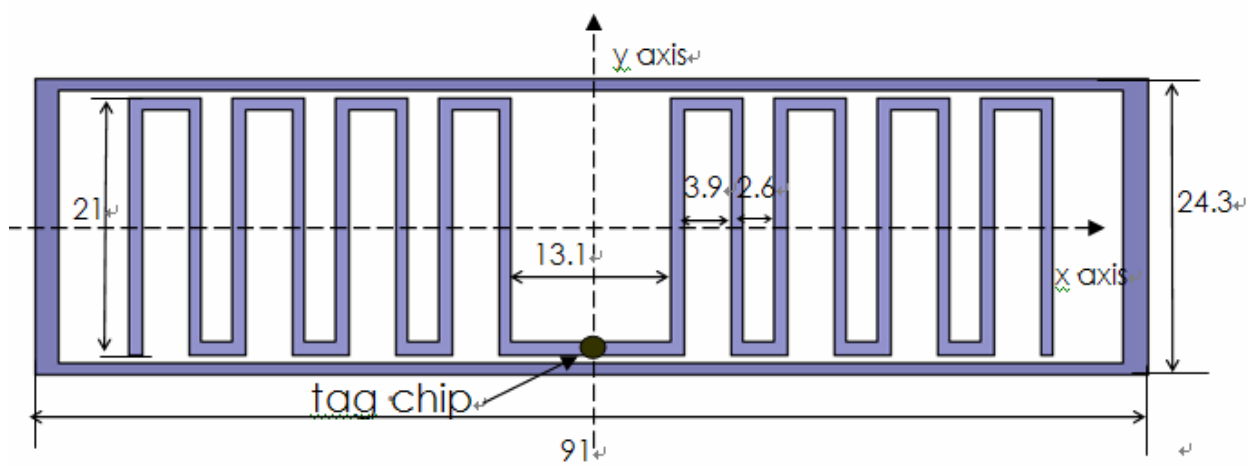

Fig. 9. Geometry of a meandered dipole antenna surrounded by the rectangular loop (dimensions in $\mathrm{mm}$ )

In our application, an UHF band tag chip with $43-\mathrm{j} 800 \mathrm{ohm}$ impedance is used, and a tag antenna connected to this chip should match the tag chip. Meanwhile the tag antenna should be small in size and easily fabricated. In Fig. 9, a meandered dipole antenna is designed, and a pair of symmetrical meandered metallic strips surrounded by a rectangular 
loop is fed. The higher real part of the impedance can be realized by the meandered dipole, while its high imaginary part can be supplied by the coupling between rectangular loop and symmetrical meandered dipole. In this way, a tag antenna with higher absolute value impedance and higher $Q$ value is designed and connected to the chip, to ensure the good power transmission. The gap of the feeding point is $0.1 \mathrm{~mm}$, the width of the metallic meandered strip and the horizontal part of the rectangular loop is $1 \mathrm{~mm}$, and the width of its vertical part is $2 \mathrm{~mm}$. The tag antenna has a thickness of $0.018 \mathrm{~mm}$.

The tag antenna is analyzed by the HFSS software, the performance of the antenna, including its impedance and radiation patterns, is calculated. The simulated results are shown in Table 1 and Fig. 10. These results show that the antenna with small size can be used as a tag antenna for the UHF band RFID chip application.

\begin{tabular}{|c|c|c|c|}
\hline Freq(MHz) & $\begin{array}{c}\text { Antenna } \\
\text { impedance } \\
\text { (ohm) }\end{array}$ & $\begin{array}{l}\text { Power reflection } \\
\text { coefficient }|s|^{2}\end{array}$ & $\begin{array}{l}\text { Power transmission } \\
\quad \text { coefficient } \tau\end{array}$ \\
\hline 900 & $36.6+j 695.2$ & 0.6365 & 0.3635 \\
\hline 901 & $37.1+\mathrm{j} 701.6$ & 0.6036 & 0.3964 \\
\hline 902 & $37.7+j 708.0$ & 0.5670 & 0.4330 \\
\hline 903 & $38.3+j 714.5$ & 0.5268 & 0.4732 \\
\hline 904 & $38.9+j 721.0$ & 0.4833 & 0.5167 \\
\hline 905 & $39.5+j 727.7$ & 0.4354 & 0.5646 \\
\hline 906 & $40.1+j 734.5$ & 0.3840 & 0.6160 \\
\hline 907 & $40.7+j 741.4$ & 0.3294 & 0.6706 \\
\hline 908 & $41.3+j 748.4$ & 0.2728 & 0.7272 \\
\hline 909 & $42.0+j 755.5$ & 0.2152 & 0.7848 \\
\hline 910 & $42.7+j 762.7$ & 0.1593 & 0.8407 \\
\hline 911 & $43.4+j 770.0$ & 0.1076 & 0.8924 \\
\hline 912 & $44.1+\mathrm{j} 777.4$ & 0.0632 & 0.9368 \\
\hline 913 & $44.8+j 785.0$ & 0.0288 & 0.9712 \\
\hline 914 & $45.5+j 792.7$ & 0.0076 & 0.9924 \\
\hline 915 & $46.3+j 800.5$ & 0.0014 & 0.9986 \\
\hline 916 & $47.1+j 808.4$ & 0.0107 & 0.9893 \\
\hline 917 & $47.9+\mathrm{j} 816.4$ & 0.0343 & 0.9657 \\
\hline 918 & $48.7+\mathrm{j} 824.6$ & 0.0707 & 0.9293 \\
\hline 919 & $49.6+j 832.9$ & 0.1166 & 0.8834 \\
\hline 920 & $50.4+j 841.4$ & 0.1695 & 0.8305 \\
\hline 921 & $51.3+j 850.0$ & 0.2255 & 0.7745 \\
\hline 922 & $52.2+j 858.7$ & 0.2822 & 0.7178 \\
\hline 923 & $53.2+j 867.6$ & 0.3381 & 0.6619 \\
\hline 924 & $54.1+\mathrm{j} 876.7$ & 0.3923 & 0.6077 \\
\hline 925 & $55.1+j 885.9$ & 0.4426 & 0.5574 \\
\hline 926 & $56.1+j 895.2$ & 0.4890 & 0.5110 \\
\hline 927 & $57.2+j 904.8$ & 0.5320 & 0.4680 \\
\hline 928 & $58.3+j 914.5$ & 0.5710 & 0.4290 \\
\hline 929 & $59.4+j 924.4$ & 0.6065 & 0.3935 \\
\hline 930 & $60.5+j 934.5$ & 0.6387 & 0.3613 \\
\hline
\end{tabular}

Table 1. The impedance and power reflection coefficient, power transmission coefficient for Tag antenna (chip impedance: 43-j800ohm) 


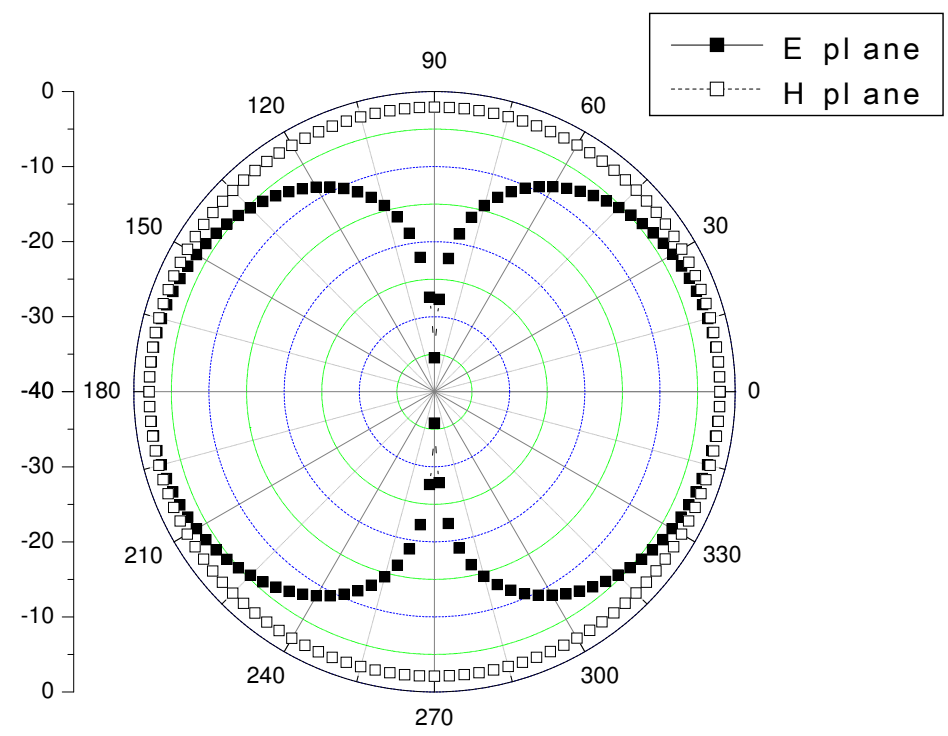

Fig. 10. Radiation pattern of the meandered dipole antenna

\subsection{Tag antenna mountable on metallic objects}

Since the RFID technology is applied in wide fields, RFID systems frequently appear in the metallic environment, and the effect of the metallic objects should be considered in designing the antenna (Penttilä et al, 2006). RFID antennas in microwave band have a defect of standing wave nulls under the impact of metallic environment. To solve the problem brought by the metallic objects, some special tag antennas should be designed. These antennas usually have a metallic ground. Some metallic objects, which make the performance of the RFID antenna worse, are modified to be as an extended part of the antenna to improve its performance. Some existing problems should be discussed.

When the traditional dipole antenna is attached to an extremely large metallic plane, its radiation will be damaged. In general, the tag antenna with a hemispherical coverage is required. In practical application, a tag antenna with low profile is frequently used, and its vertical current is limited. In Fig. 11, when a normal dipole antenna approaches closely the metallic surface, an inductive current in opposite direction is excited, and the radiation induced by the current will eliminate the radiation of the dipole, resulting in that the tag cannot be detected or read. As a class of antennas, the microstrip antenna may be a good choice for being mounted on the metallic surfaces and identifying the metallic objects. For ordinary tag chip, a balun or other circuit is needed to feed the antenna. Here, based on the dipole antenna, two design schemes for the metallic surfaces are proposed. One is a modification to the Yagi antenna, and the other is a dipole Antenna backed by an EBG structure. A substrate with high dielectric coefficient is sandwiched between the dipole and the metallic surface, its thickness will reverse the orientation of the inductive current, and the radiation is strengthened. An EBG structure can depress the primary inductive current, 
the radiation of the dipole will be available, and the metallic surface of the identified object is also the ground of the EBG structure.

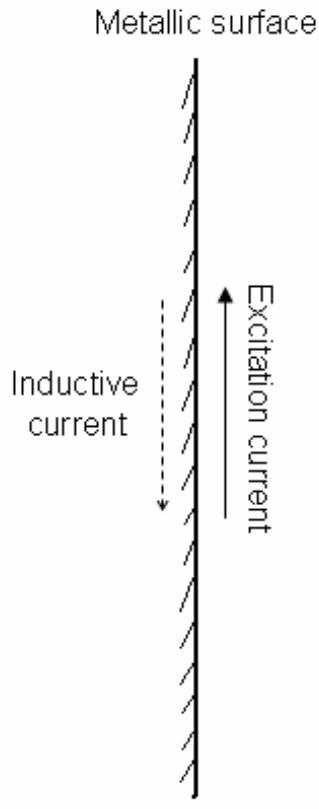

(a)

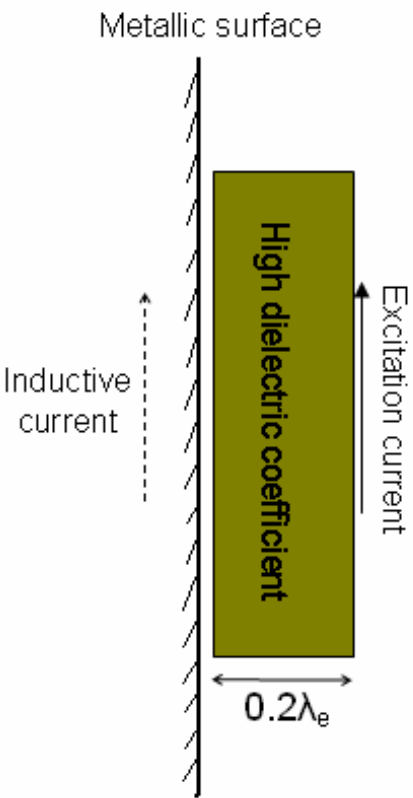

(b)

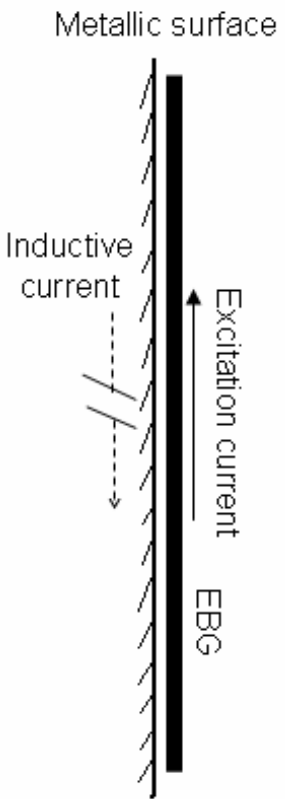

(c)

Fig. 11. Design scheme for the tag antenna on metallic surfaces
(a) Excitation current nearby the metallic surface; (b) Scheme based on the Yagi antenna
(c) Scheme based on the EBG structure

According to the introduced schemes, three tag antennas are designed for three tag chips with impedances 15-j20 ohm (chip 1), 6.7-j197ohm (chip 2), and 43-j800 ohm (chip 3), respectively. The tag antenna based on the Yagi antenna is shown in Fig. 12, and the geometry of the active dipole (Qing \& Yang, 2004a) is also given in Fig. 13. In Fig.12, the active dipole is attached on the substrate with the relative dielectric coefficient $\varepsilon r=10.2$. The width of the metallic strip is $0.8 \mathrm{~mm}$.

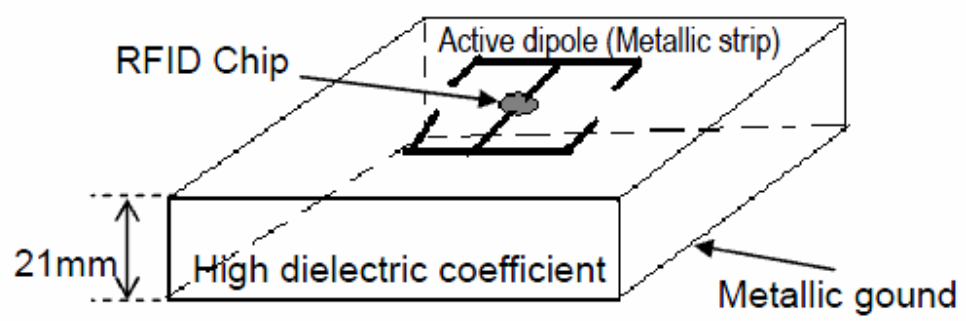

Fig. 12. The tag antenna for chip 1 based on the Yagi antenna 


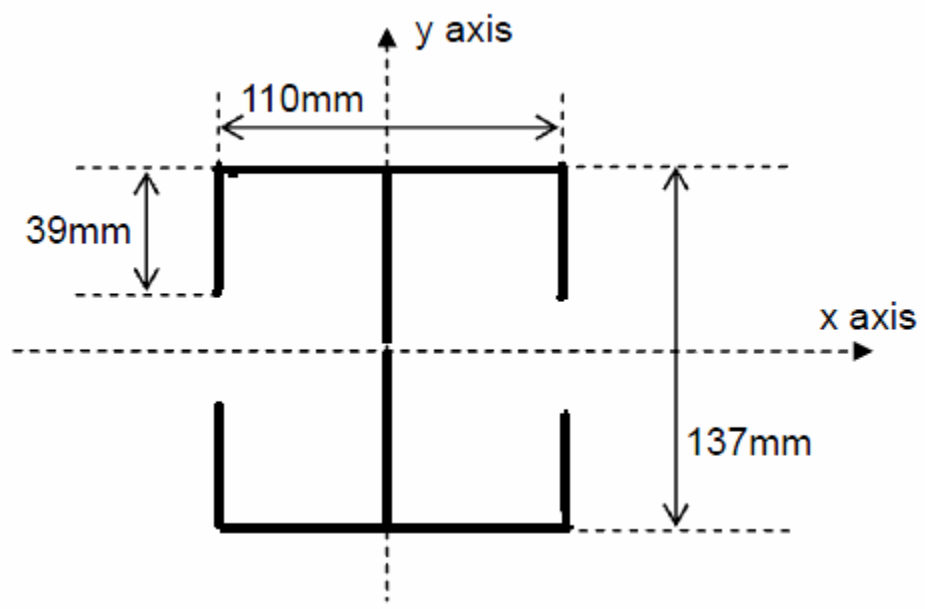

Fig. 13. Geometry of the active dipole (dimensions in $\mathrm{mm}$ )

The antenna shown in Fig. 12 is analyzed by the HFSS software. The calculated antenna impedance matches the chip impedance $15-\mathrm{j} 20 \mathrm{ohm}$ in UHF band. Radiation patterns of the tag antenna are also calculated and shown in Fig. 14.

To design the antenna for chip 2 with $6.7-\mathrm{j} 197 \mathrm{ohm}$ impedance, the structure parameters are adjusted. The designed dipole is shown in Fig. 15, and its simulated radiation patterns are presented in Fig. 16.

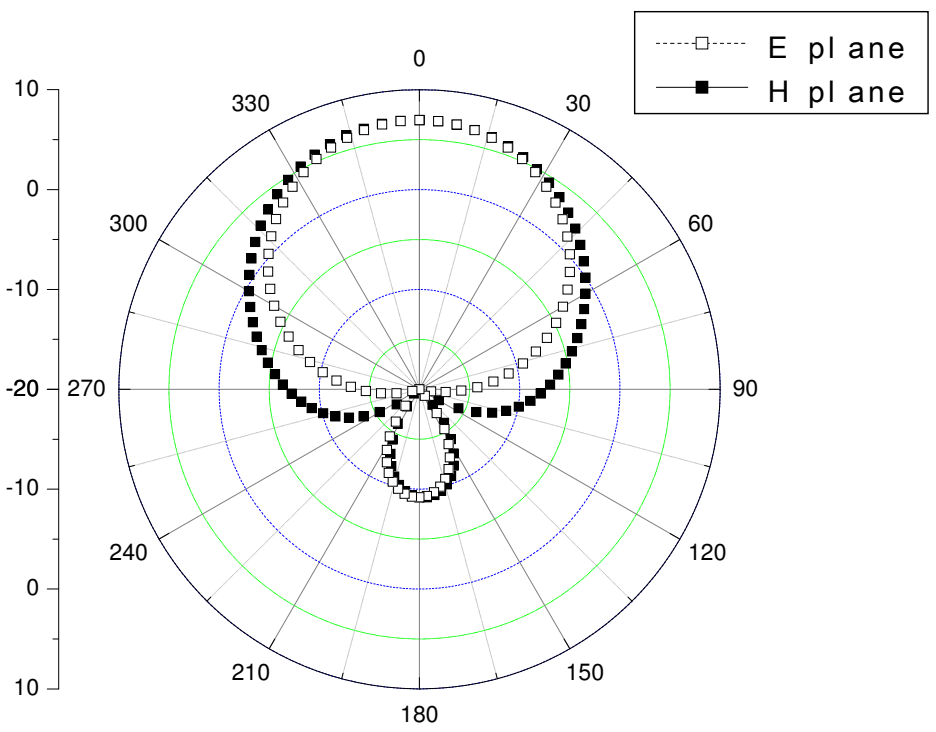

Fig. 14. Radiation patterns of the tag antenna for chip 1 


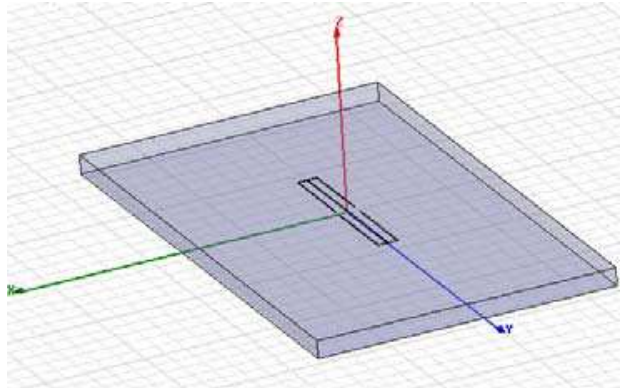

(1) The tag antenna and the substrate

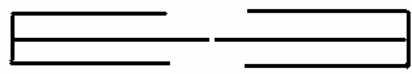

(2) The active dipole

Fig. 15. Geometry of the tag antenna for chip 2

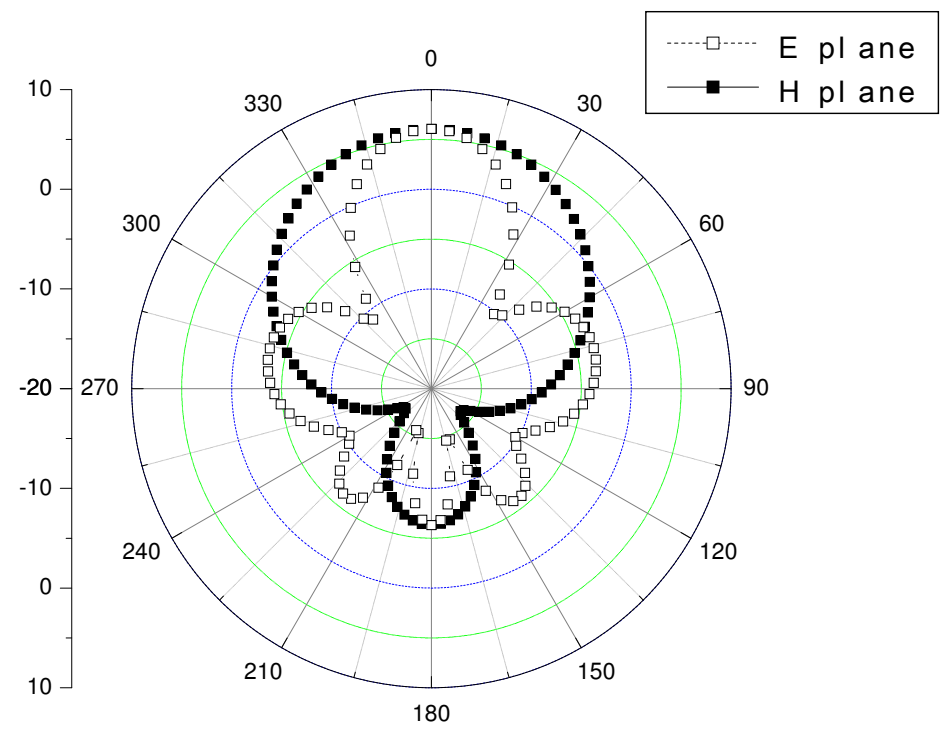

Fig. 16. Radiation patterns of the tag antenna for chip 2

Similar tag antenna can also be designed based on the EBG structure (Abedin \& Ali, 2005a, 2005b, 2006; Yang \& Rahmat-Samii, 2003) like the tag antenna shown in Fig. 12. The EBG structure is attached to the surface of the metallic object, and the tag dipole antenna like the active dipole in Fig. 13 is placed on the EBG structure formed by $5 \times 7$ elements, as shown in Fig. 17. This structure is analyzed at frequency $915 \mathrm{MHz}$ in the UHF band, and its radiation patterns are calculated, which are shown in Fig. 18. The simulated impedance values show that the tag antenna matches the chip 3 with impedance $43-\mathrm{j} 800 \mathrm{ohm}$. The relative dielectric coefficient of the substrate of the EBG structure is 2.65, its thickness is $2 \mathrm{~mm}$, and the total thickness of the tag antenna is $15 \mathrm{~mm}$. The low cost tag antenna with low profile will be fabricated. 


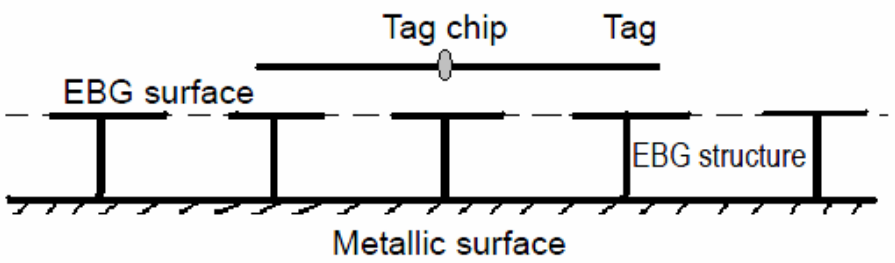

Fig. 17. The tag antenna backed by the EBG structure for chip 3

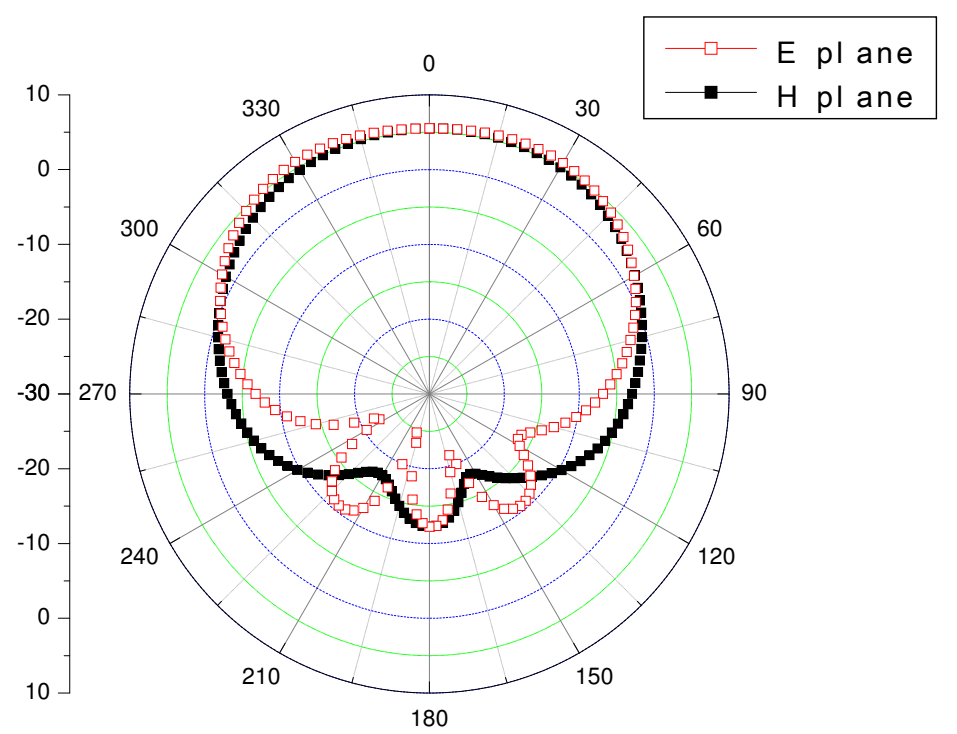

Fig. 18. Radiation patterns of the dipole backed by the EBG structure for chip 3

In this section, design of the tag antenna for the metallic surface is presented, and several cases are described and discussed. Other types of tag antenna mounted on the metallic objects, such as the inverted-F antenna and its modifications are also popular. For the details about these antennas, refer to Kim et al., 2005; Son et al., 2006; Ukkonen, Sydänheimo et al., 2004; Hirvonen et al., 2004; and Ukkonen, Engels et al., 2004.

\section{Circular polarization modulation and design of the circularly polarized antennas}

\subsection{Circularly polarized reader antenna and circular polarization modulation}

Generally the object to be identified or the tag does not point to a certain direction, so the circularly polarized reader antennas are usually used (Raumonen et al., 2004) to receive signals from all directions and do not miss the mismatched polarized signals of the moving object. The linearly polarized reader receives more than $3 \mathrm{~dB}$ power, when the polarizations of the tag and the reader are matched. In some wireless communication systems, the circular 
polarization modulation (Fries et al., 2000; Kossel, Kung, et al., 1999), which is well adapted to the low rate RFID systems, is another choice that can reduce the requirement of the frequency band, and simplifies the data communication, as shown in Fig. 19. Therefore, the antennas, used for the reader and the tag, should be dual circular polarization antennas with two ports in the RFID system.

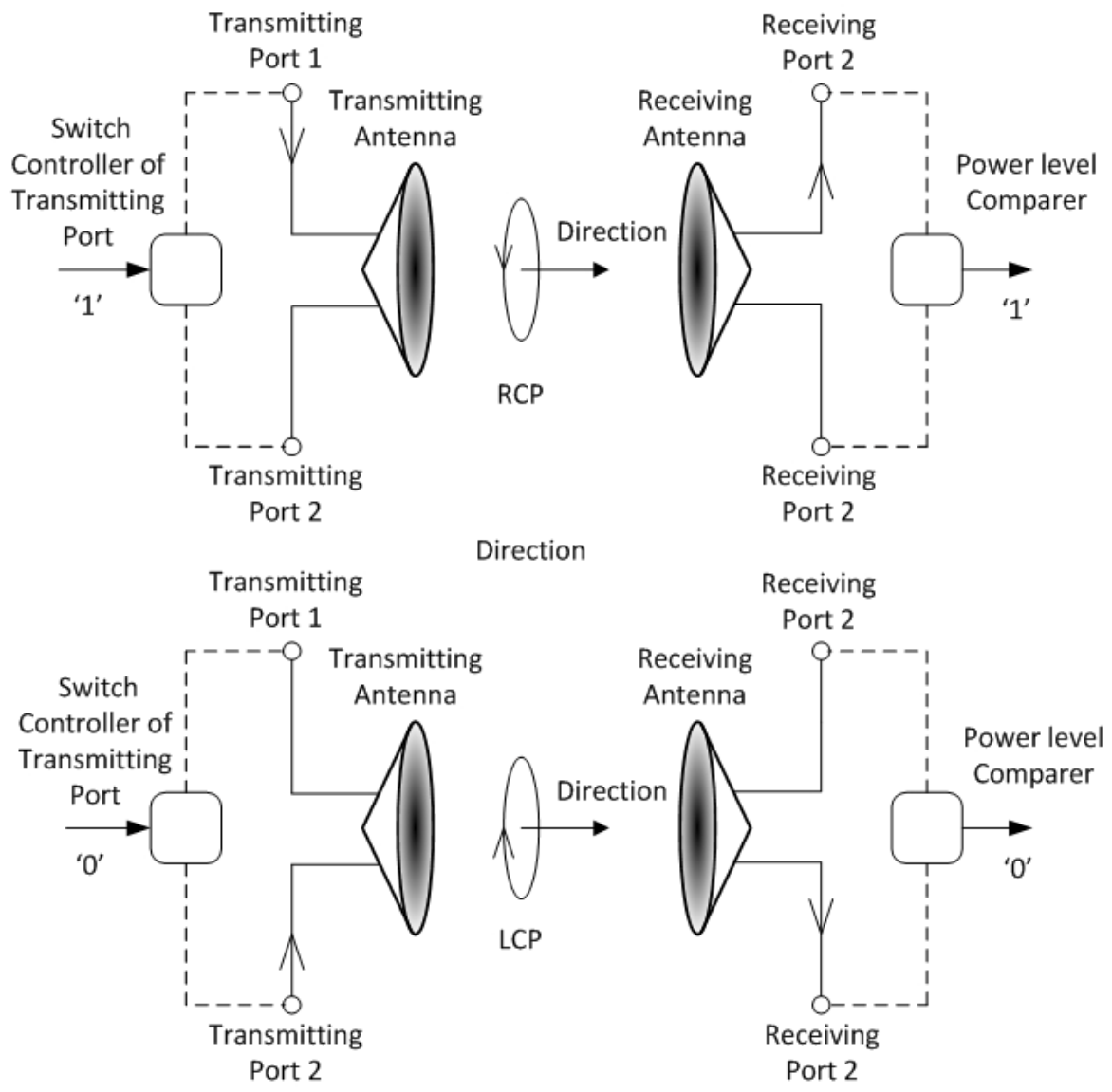

Fig. 19. Principle chart of the circular polarization modulation

Helix antennas and microstrip antennas are widely used as the circularly polarized reader antenna for one-port applications. The helix antenna has some advantages, such as low cost and simple design, except its larger physical size. The low profile helix antenna with the EBG structure instead of the metal ground plane can be used for the RFID reader (Raumonen et al., 2004).

The circular polarization modulation is always used in the RFID system, and its basic principle is that a logical zero is transmitted as the left-hand circularly polarized (LHCP) wave, and a logical one is represented by a right-hand circularly polarized (RHCP) wave. Both reader and tag can use circularly polarized antennas with switchable polarizations. Cross polarization isolation has the significant effect on the performance of the whole 
system. The maximum transmission distance can be expanded more than $20 \%$, if the cross polarization level (XPL) reaches up to $20 \mathrm{~dB}$ from $5 \mathrm{~dB}$. In the backscattering modulation system, the incident LHCP wave illuminated to the tag is modulated and backscattered into the RHCP wave, and then retransmitted to the reader. Relative to the system where the linearly polarized tag antennas are used, the signal received by the reader in the circular polarization modulation system will raise $6 \mathrm{~dB}$. In spite of what kind of the modulation is used, the system should have higher polarization isolation. At the same time, the tag antenna should have higher port isolation, which can reduce the interference between the transmission channel and the receive channel.

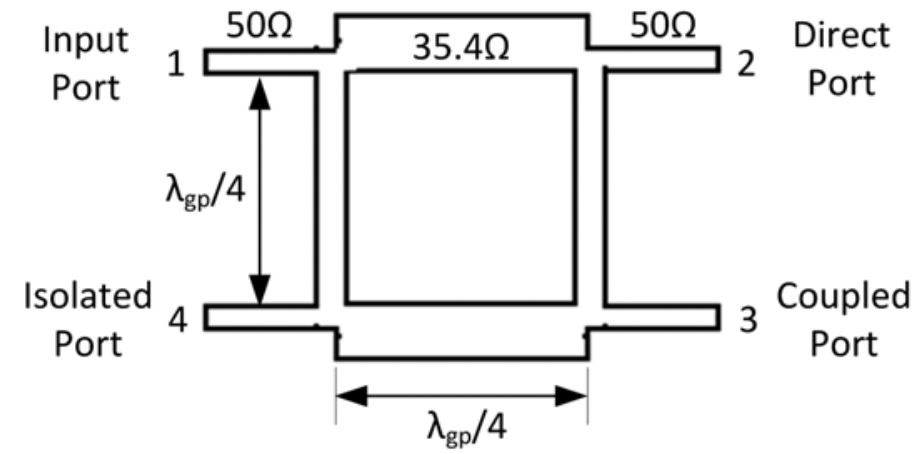

Fig. 20. The $3 \mathrm{~dB}$ branch line directional coupler structure

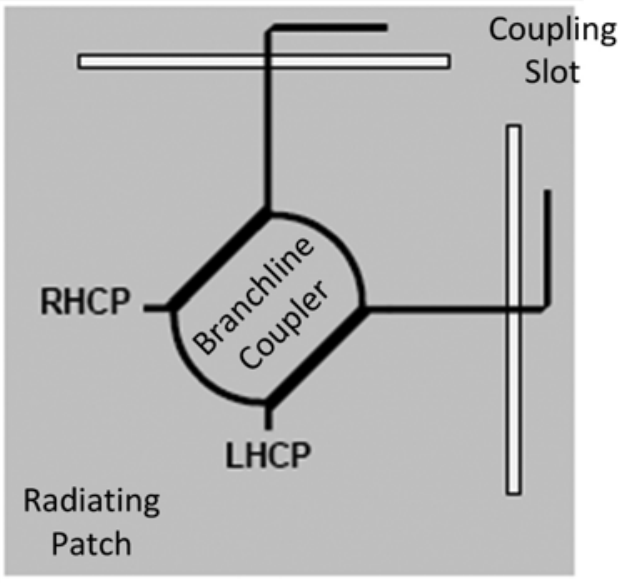

Fig. 21. Microstrip antenna with coupling slot based on the branch line coupler

The traditional design of the dual-port dual-polarization antenna (Kossel, Benedickte et al, 1999; Qing \& Yang, 2004b; Sharma et al., 2004) is based on the branch line directional coupler, in which the electrical fields in two output branches have identical voltages and a $90^{\circ}$ phase shift, and has high isolation between two output ports, as shown in Fig. 20. When the impedances of the four ports are matched very well and the signal inputs from Port 1 , Port 4, called the isolation port, has no output signal, and there is a $90^{\circ}$ phase shift between Port 2 and Port 3. The dual circularly polarized antenna, as shown in Fig. 21, is a microstrip 
patch antenna, which uses a branch line coupler to feed the orthogonal slot apertures and to realize the required $90^{\circ}$ phase shift. Four different circularly polarized antennas are shown in Fig. 22. The multilayered antennas employ two substrates, the patch layer and the feed layer, and a ground plane with slot apertures between two substrates, as shown in Fig. 23. The patch antennas can realize the dual circular polarization by using the branch line coupler or the microwave branches to feed the slot apertures with the required phase shift.

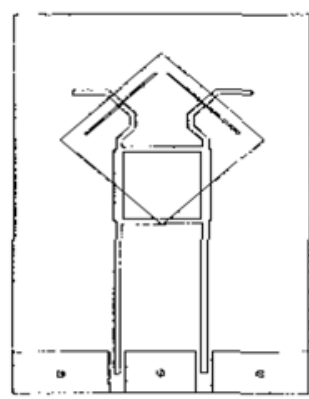

A

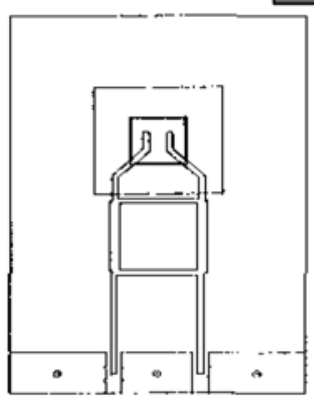

C

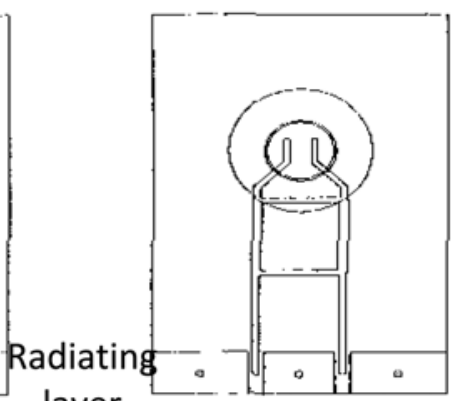

B

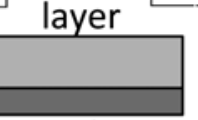

\section{.} (1) .

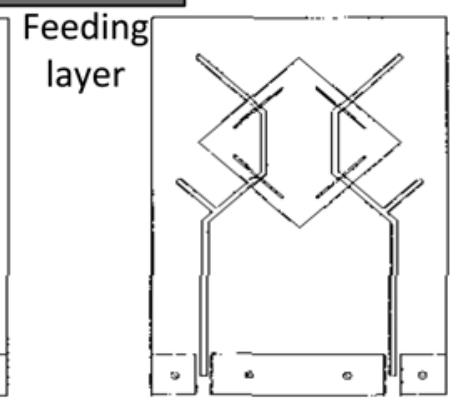

$\mathrm{D}$

Fig. 22. Four dual-port dual circularly polarized antennas

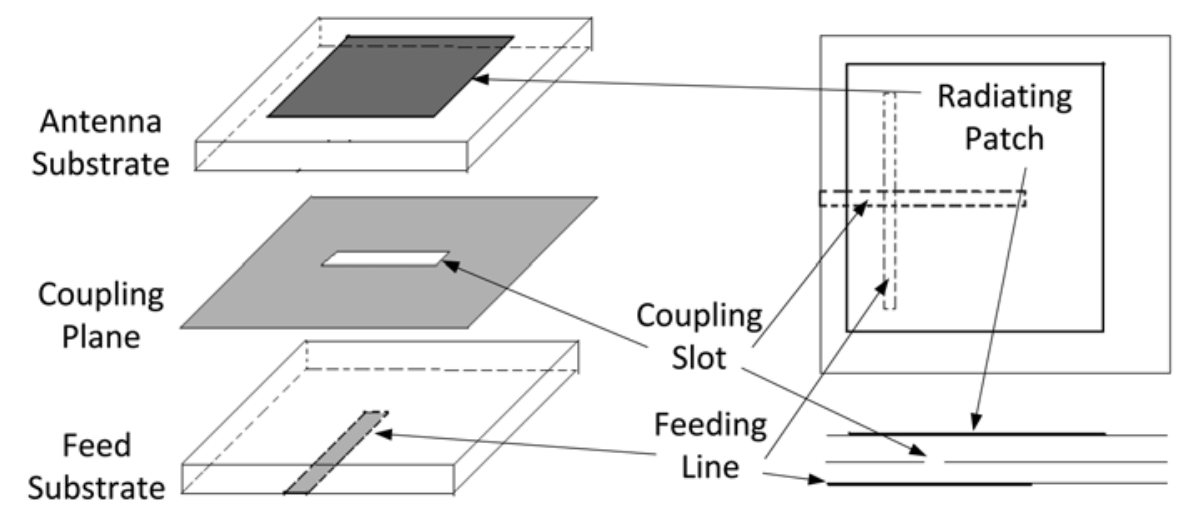

Fig. 23. Multilayered microstrip antenna structure 


\subsection{A compact dual circularly polarized antenna}

In order to realize low profile and part the feed line from the patch, the slot aperture microstrip antenna is commonly used. For this kind of antennas, the designer could select different substrates for the feed and patch layers, according to the application requirements of the microwave integrate circuits. As shown in last section, dual circularly polarized antennas for the RFID system in microwave band are fed by two orthogonal and isolated slot apertures, based on the branch line directional coupler or other complex microwave networks. However, the configuration of the antenna presents a structural bottleneck, i.e. the isolated slots and feeding network limit the miniaturization of the antennas, and the microwave network with complex circuits occupies the larger space. It is well known that RFID antennas can achieve long distance propagation of electromagnetic waves, but sometimes have the problem such as standing wave nulls. Therefore, the antennas should be integrated with the loop, which could transmit power to the low frequency system through the inductance coupling, and reduce the size of the feed network. In order to get rid of the bottleneck on the miniaturization of the antennas, we should design the compact slot aperture microstrip antenna with simple feed network to accomplish the dual circular polarization. In this section, we present a compact dual circularly polarized antenna for RFID systems.

In the RFID system, the rate of the data communication is not so high, sometimes just a few bites. Therefore the circular polarization modulation can be used in the narrow bandwidth communication to simplify the data communication. It is necessary to design dual circularly polarized antenna with two well-isolated ports for the circular polarization modulation.

In order to miniaturize the dimensions of the antenna, as shown in Fig. 24, a dual circularly polarized microstrip antenna fed by crossed slots without the branch line coupler is proposed (Zhang, Chen., Jiao \& Zhang, 2006), which is an optimal choice for the RFID system with larger bandwidth and the smaller size. The coupling aperture for the circularly polarized antenna comprises two crossed slots (Aloni E. \& Kastener, 1994) in the ground plane, with four arms of the aperture fed serially by a single microstrip line located underneath the ground plane. The microstrip line feeds the four arms with $90^{\circ}$ progressive

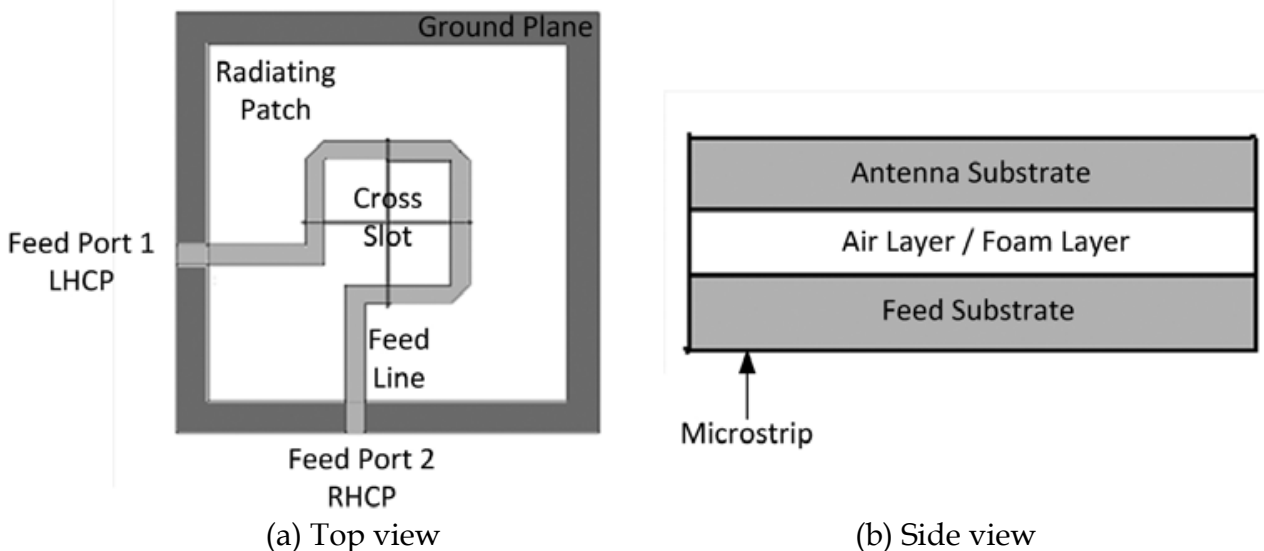

Fig. 24. Structure of the dual circular polarized antenna 
phase difference. The symmetric arrangement makes the antenna achieve easily the dual circular polarization. The design method has been widely used for the antenna at $2.45 \mathrm{GHz}$ in the RFID system.

In order to reduce the cost, the air layer used to replace the foam material, as shown in Fig. 24 , is sandwiched between two substrate layers with the same dielectric constant $\varepsilon r=2.65$. HFSS simulation results show that the performance of the antenna cannot satisfy the requirement for the RFID system. Thus, the structure of the antenna should be modified to improve its performance. As a result, a corner-truncated square patch (Wang, 1989) is used to replace the normal square patch, which will improve the circular polarization performance of the antenna and its port characteristics. At the same time, we cut a square aperture in the centre of the patch to restrict the current and to improve the port isolation. Steps of the patch evolution from the square to the corner-truncated square with a square aperture are shown in Fig. 25, and the final antenna structure is shown in Fig. 26. Simulated performance indices of these three patch antennas are given in Table 2, which indicate the effectiveness of the patch modifications.

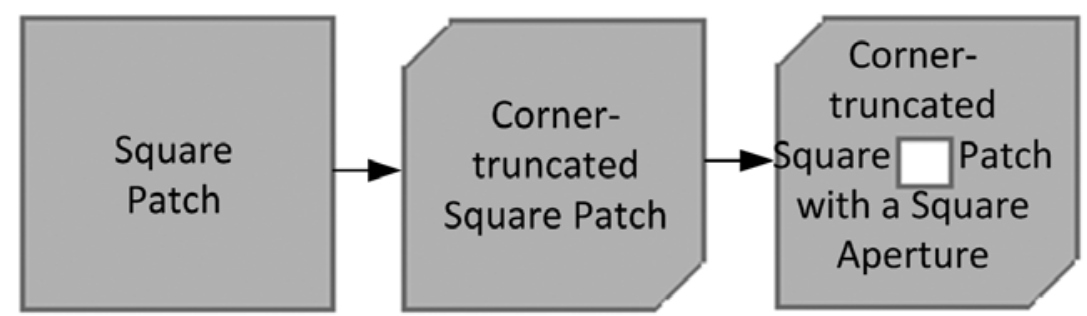

Fig. 25. Steps for the patch modifications

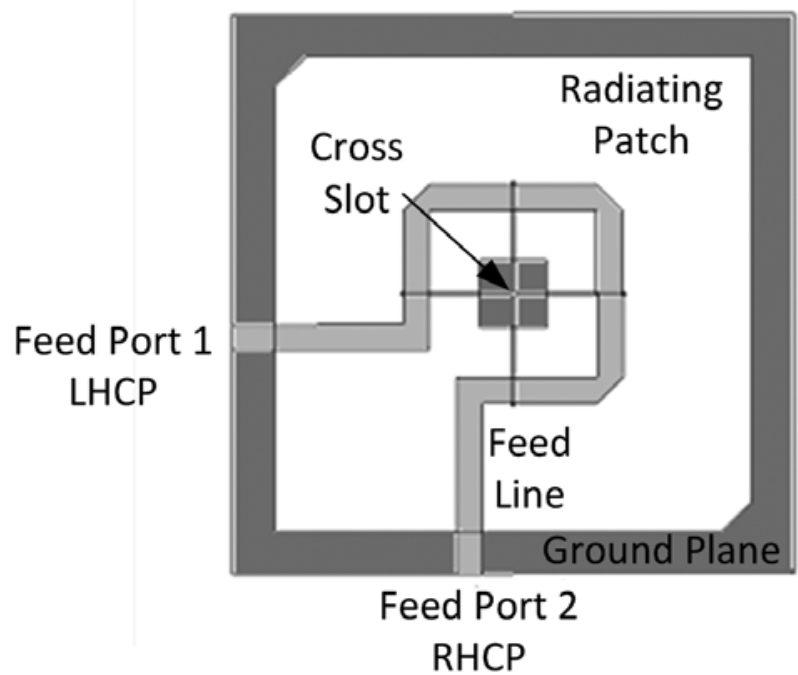

Fig. 26. Geometry of the antenna after modifications 
We now determine the dimensions of the corner-truncated square patch antenna with a square slot. First we adjust the dimension of the patch to get the maximum gain, keeping the other parameters of the antenna fixed. We then adjust the length and width of the slots to improve the port characteristics. Because it affects the coupling between the microstrip and the patch more seriously, the length of the slots should be adjusted in advance. Finally, by adjusting the square aperture and the corner of the patch, the antenna with better performance is obtained. The total size of the antenna is $60 \mathrm{~mm} \times 60 \mathrm{~mm} \times 3 \mathrm{~mm}$. The width of the corner-truncated square patch with a square aperture is $51 \mathrm{~mm}$, and each layer is $1 \mathrm{~mm}$ thick. The microstrip line has a width that makes the transmission line have $50 \Omega$ characteristic impedance. The length and width of the aperture are $24 \mathrm{~mm}$ and $0.316 \mathrm{~mm}$, respectively.

\begin{tabular}{c|ccc}
\hline Patch modifications & Axial Ratio $(\mathrm{dB})$ & S11 $(\mathrm{dB})$ & S21 $(\mathrm{dB})$ \\
\hline Primary square patch & 3.64 & -11 & -17 \\
Corner-truncated square patch & 0.73 & -20.2 & -19.2 \\
Final patch structure & 1.07 & -20.4 & -30 \\
\hline
\end{tabular}

Table 2. Antenna parameters during the modification

We have tested a prototype of the compact dual circularly polarized antenna shown in Fig. 29. The measured results are shown in Figs. 27 and 28. Comparison between the simulated results and the measured data shows that the measured $S$ parameters at two ports agree well with the simulated results. The measured S21 is better than the simulated one, however the measured S11 is worse than the simulated one. There is a tradeoff between the return loss and the port isolation. From the measured radiation patterns, we can see that the cross polarization levels better than $-15 \mathrm{~dB}$ are achieved. Although the measured cross polarization levels cannot reach the simulated circular polarization performance, they meet the requirements of the RFID system. The antenna can be used to realize the circular polarization modulation for the RFID systems.

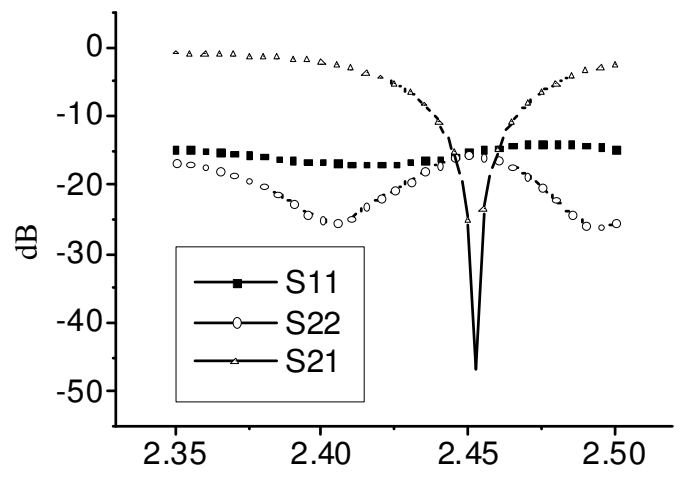

Fig. 27. Measured S parameters at two ports 
Simulated and measured results for the compact dual circularly polarized aperture coupled patch antenna show that the compact structure meets the requirements for the RFID system. For the antenna with smaller size, a port decoupling better than $20 \mathrm{~dB}$ and a good circular polarization are achieved by the coupling and feeding technique, without using the microstrip branch line coupler or other complex feed networks. The design can save more space for the IC layout, and the miniaturization of the antenna is realized, which is very important for the integration of the RFID system at the microwave frequency and low frequency bands. The dual circularly polarized antenna with the compact structure is not only applicable to the normal RFID systems, especially in some identification card applications, but also suitable for using in some wireless communication systems.

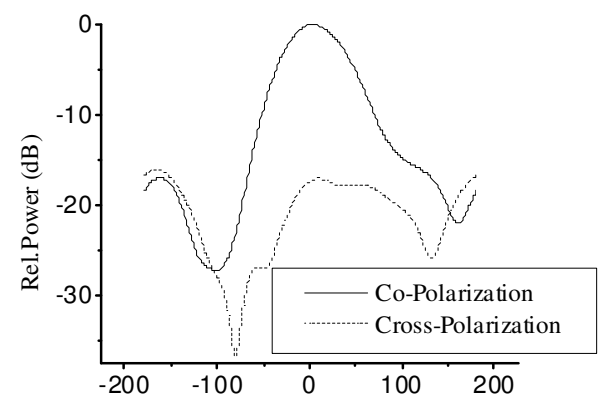

(a)

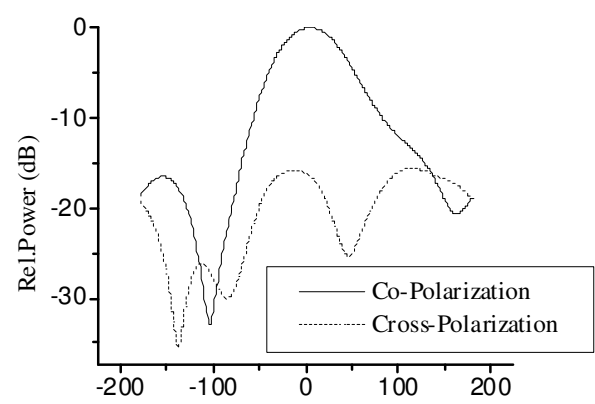

(b)

Fig. 28. Measured radiation patterns at two ports

(a) Excitation in LHCP port; (b) Excitation in RHCP port
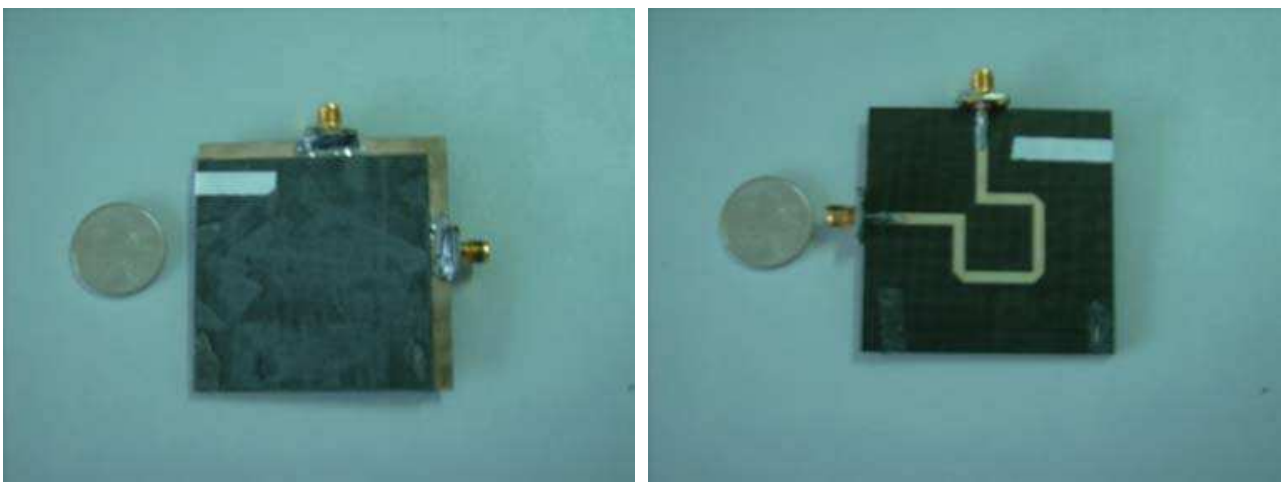

Fig. 29. Photograph of the compact dual circularly polarized antenna prototype

\section{Design of antennas for the RFID tag in microwave bands}

According to the design of the tag and the reader at the microwave band, special chips for the application of the RFID system are immature and seldom used in industry. Thus engineers usually use specific ASICs available in the market for some special RFID systems, 
and sometimes use the coaxial cable to connect the ASIC with the antenna, whose impedance is $50 \Omega$.

A radio-frequency identification system consists of tags and readers, and readers communicate wirelessly with the tags to obtain or transfer the information. The data sent by the reader is modulated and backscattered from a number of tags. In some cases, the reader changes the data stored in the tag. Several frequency bands, such as $125 \mathrm{KHz}, 13.56 \mathrm{MHz}$, $869 \mathrm{MHz}, 902-928 \mathrm{MHz}, 2.45 \mathrm{GHz}$ and $5.8 \mathrm{GHz}$ bands, have been assigned to the RFID applications. As the operating frequency for the RFID systems rises into the microwave bands, the antenna design becomes more acute and essential (Chen \& Hsu, 2004; Liu \& Hu, 2005).

The tag, which includes the antenna and a microchip transmitter, must be low in profile, low in cost and small in size for the valuable and easy use, when it is attached to an object to be identified. Therefore, a suitable antenna used in the tag becomes more and more important. As the RFID technology continues to be widely used in applications, especially meeting the reliability, the anti-interfere and the other special requirements, the systems that are able to work at two bands, such as $2.45 \mathrm{GHz}$ and $5.8 \mathrm{GHz}$ bands, are expected.

The reader with a single antenna is used for both data transmission and receiving, which needs severe operational requirements to the reader RF front end, since the communication takes place in both directions at the same time. The reader may use two antennas for the communication, one antenna for the data transmission and the other antenna for the data receiving (Penttilä et al, 2006). This choice can reduce the realization difficulty from the hardware point of view. In addition, there may have more than two antennas in the reader. In this case, the reader must follow a certain sequence to switch on an antenna at a time, while keeping other antennas switched off, to avoid interferences between these antenna signals.

The approach for using two antennas in the reader is based upon the following reasons:

1. The transmitting electromagnetic wave from the reader does not vanish, when the reflecting wave from the tag reaches the antenna of the reader in the single antenna systems.

2. The reader definitely has less sensitivity than the radar, and the transmitting wave of the reader has much more power than the receiving wave from the tag. Thus the circulator or the directional coupler should be designed to meet higher requirements.

3. The backscattered wave has the lower intensity than the transmitting wave, so the circulator or the directional coupler should meet higher isolation in order to separate the signals.

4. The reader must be inexpensive. Based on the aforementioned reasons, the reader is hard to realize.

Two antennas, one for transmitting and the other for receiving, can overcome these problems. However, a higher isolation between the antennas for the communication should be required, and the smaller tag makes the isolation hard to realize. Microwave frequency bands used in the RFID system include $2.45 \mathrm{GHz}$ and $5.8 \mathrm{GHz}$ bands, which have the similar transmission characteristic. Therefore the design method for the antenna operating in two frequency bands is also similar. If the transmitting antenna and the receiving antenna work at two frequency bands separately, it is easy to realize a narrow frequency band antenna for the reader, and then higher isolation can be achieved between the transmitting antenna and the receiving antenna. On the other hand, the RFID system only uses these two frequency 
bands, does not interferes signals at other close frequency bands assigned by global International Organization for Standardization (ISO), thus satisfies the EMC requirements. We present a two-antenna system which can operate simultaneously at 2.45 and $5.8 \mathrm{GHz}$ bands, as shown in Fig. 30. The tag antenna, worked at two frequency bands, not only can receive the transmitting signals from the reader at $5.8 \mathrm{GHz}$, but also can transmit signals with the tag code at $2.45 \mathrm{GHz}$, which are received and demodulated by the reader to obtain the tag information.

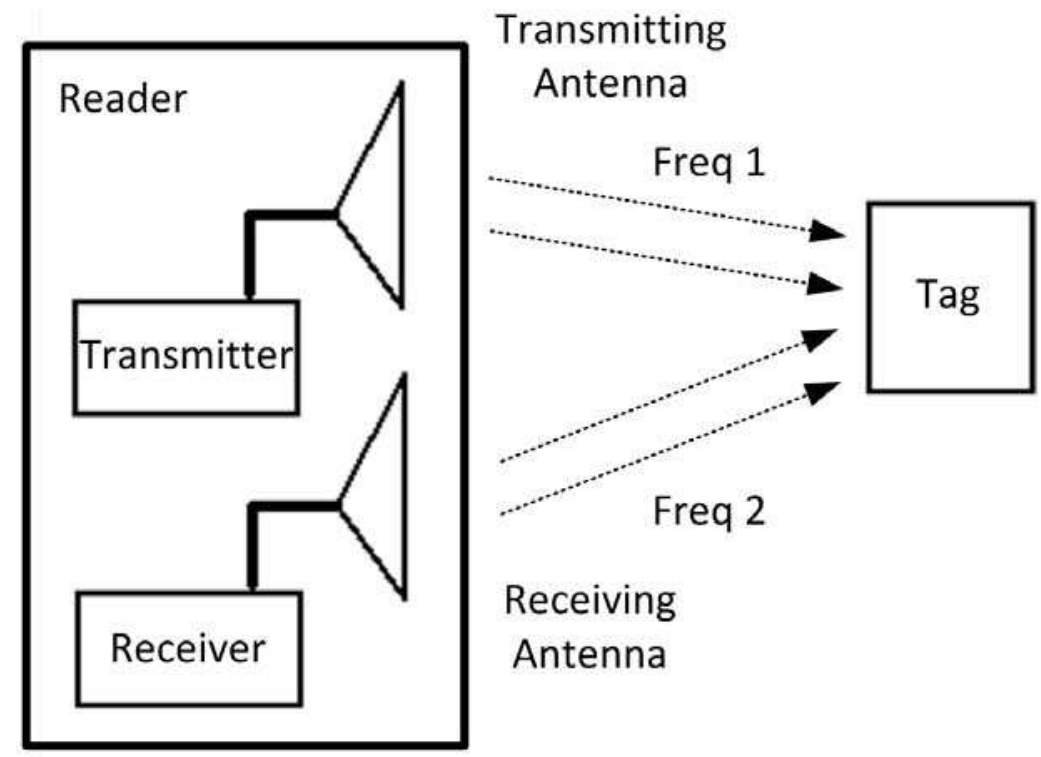

Fig. 30. The dual antenna system in the RFID system

We present a dual-band folded-slot antenna with RF performance suitable for the RFID tag use at 2.45/5.8 GHz (Zhang, Jiao \& Zhang, 2006), which consists of a folded slot with a open end and a coplanar waveguide (CPW)-fed structure such that only a single-layer substrate is required for the antenna. By properly adjusting the folded slot on the rectangular patch, compact antenna size, good match at two frequency bands and the radiation characteristics suitable for the RFID application at 2.45 and $5.8 \mathrm{GHz}$ could be achieved.

The geometry of the proposed CPW-fed folded-slot monopole antenna with the open end is shown in Fig. 31. The antenna has a simple structure with only one layer of FR4 dielectric substrate (thickness $1 \mathrm{~mm}$ and relative permittivity 4.4) and metallization. The antenna is symmetrical with respect to the longitudinal direction; a folded slot splits the rectangle patch into a double C-shaped ground, and a balance-shaped strip that is fed by the CPW and connects to an SMA forms a monopole structure. Clearly, as the radiating element of this antenna, the balance-shaped strip is thus separated from the ground plane by the folded slot with the open end. The strip can produce two resonant frequencies by adjusting the location of its double arms. The balance-shaped strip is chosen to be of height $31 \mathrm{~mm}$, which is close to one-quarter wavelength in free space at $2.45 \mathrm{GHz}$, while the top part of the balance-shaped strip above the location of the double arms is chosen to be of height $12 \mathrm{~mm}$, which is also close to one-quarter wavelength in free space at $5.8 \mathrm{GHz}$. 


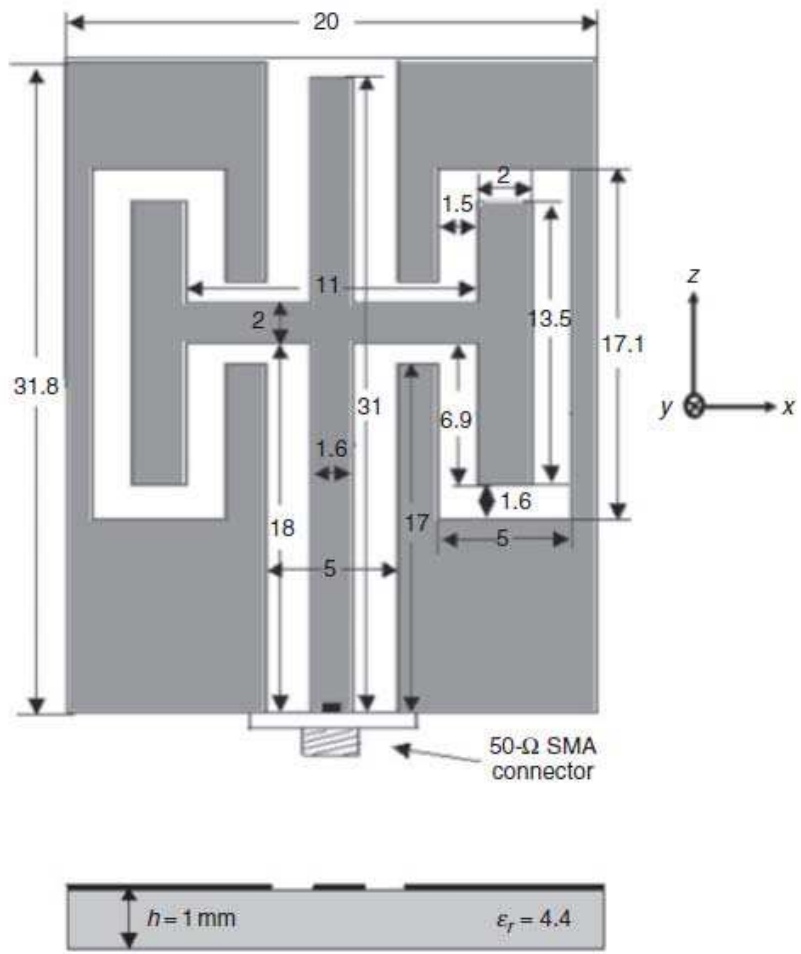

Fig. 31. Geometry of the proposed antenna with open end. The dimensions (in millimetres) shown in this figure are not to scale.

We first study the dimensions of the antenna by the simulation with the aid of HFSS electromagnetic software, analyze its performance by XFDTD simulation tool, and then adjust them by the experiment. Finally, the dimensions of the fabricated antenna are chosen with height $32 \mathrm{~mm}$ and width $20 \mathrm{~mm}$, and details of the structure are shown in Fig. 31. For the balance-shaped strip, the top end of the vertical section with strip width $1.6 \mathrm{~mm}$ and length $31 \mathrm{~mm}$ is chosen to be open, and the other sections of the strip are adjusted to achieve good match at these two frequencies. The CPW feedline, with a signal strip of width $1.6 \mathrm{~mm}$ and length $18 \mathrm{~mm}$, and a gap distance of $1.7 \mathrm{~mm}$ between the signal strip and the coplanar ground plane, is chosen to feed the dual-band monopole antenna centrally from its bottom edge.

The prototype of the proposed dual-band CPW-fed folded-slot antenna with optimal geometrical parameters, as shown in Fig. 32, is fabricated and tested. The performance of the antenna is also simulated with the aid of two electromagnetic simulators, HFSS and XFDTD. In Fig. 33, the measured and simulated frequency responses of the return loss at two bands for the proposed design are compared, and the measurement is made with a Wiltron 37269A network analyzer. As can be seen from the measured results, the antenna is excited at 2.45 GHz with a $-10 \mathrm{~dB}$ impedance bandwidth of $320 \mathrm{MHz}(2.36-2.68 \mathrm{GHz})$ and at $5.8 \mathrm{GHz}$ with an impedance bandwidth of $260 \mathrm{MHz}(5.73-5.99 \mathrm{GHz})$. However, the measured results show that the resonant modes are excited at 2.51 and $5.85 \mathrm{GHz}$ simultaneously, which are 
almost the same as that from simulations. The measured radiation patterns at these two operating frequencies are presented in Figs. 34 and 35, respectively. The measured results show that the radiation patterns of the antenna are broadside and bidirectional in the Eplane and almost omnidirectional in the H-plane ( $\mathrm{x}-\mathrm{y}$ plane). The measured peak antenna gains of the antenna at 2.45 and $5.8 \mathrm{GHz}$ are -1.8 and $2.3 \mathrm{dBi}$, respectively. Agreement between measurement and simulation is generally good, and the proposed design has sufficient bandwidth to cover the requirement of the RFID dual-band $2.45 / 5.8 \mathrm{GHz}$ system.

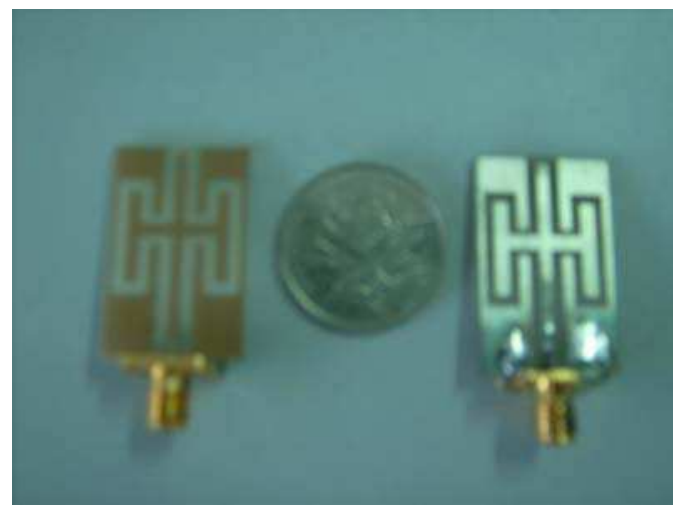

Fig. 32. Photograph of the dual band tag antenna prototype

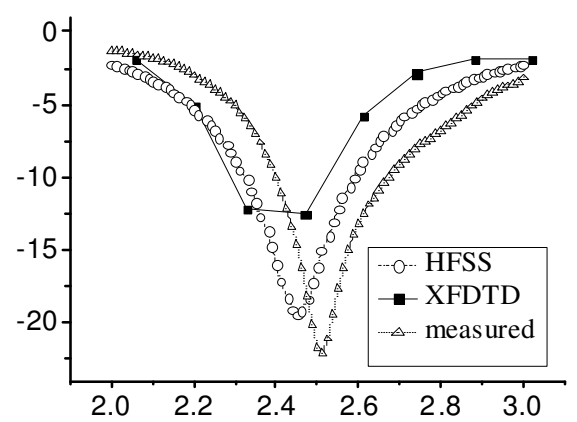

(a) $2.45 \mathrm{GHz}$ band

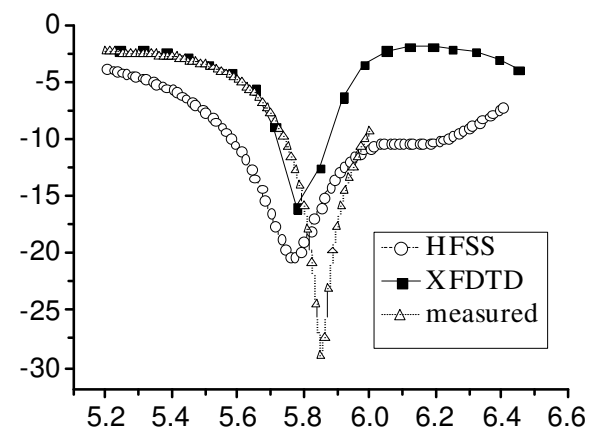

(b) $5.80 \mathrm{GHz}$ band

Fig. 33. Measured and simulated frequency responses of the input return loss for the proposed antenna

A dual-band CPW-fed monopole antenna has been proposed and implemented. With the open end and the balance-shaped strip fed by the CPW connecting to an SMA, the proposed antenna can be designed to operate at the 2.45 and $5.8 \mathrm{GHz}$ bands, and to have a corresponding bandwidth of $13.1 \%$ and $4.5 \%$, respectively. A good radiation performance is also achieved. The low-cost antenna is only $32 \mathrm{~mm} \times 20 \mathrm{~mm}$ in size, mechanically robust, and easy to fabricate and integrate with the application-specific circuit. This design is not only suitable for the dual-band RFID systems, but also applicable to the dual-band communication systems for WLAN applications. 


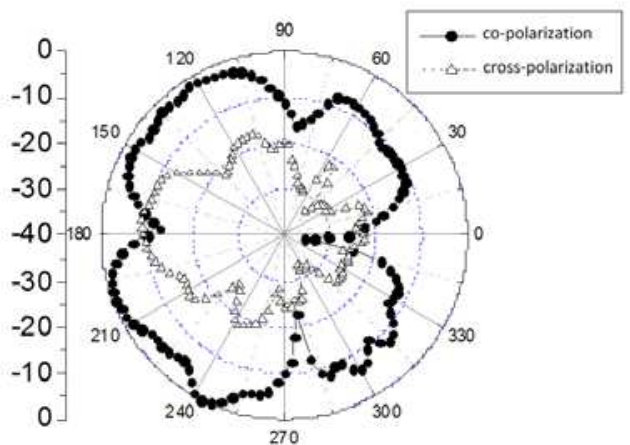

(a) E-plane pattern

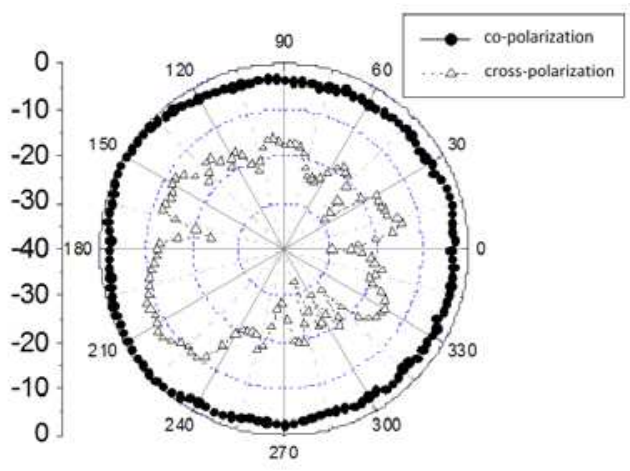

(b) H-plane pattern

Fig. 34. Measured far-field radiation patterns at $2.45 \mathrm{GHz}$ for the proposed antenna

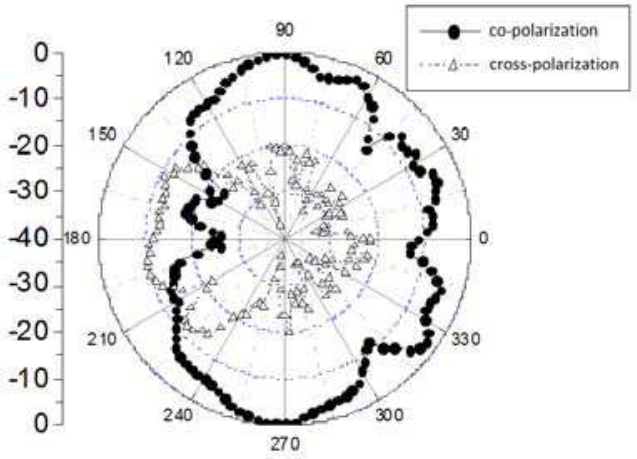

(a) E-plane pattern

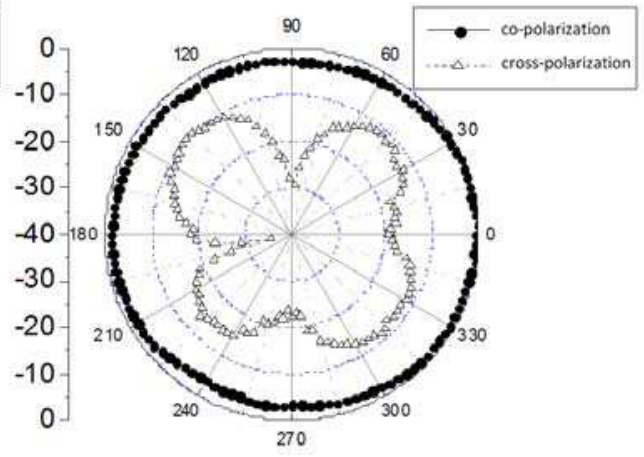

(b) H-plane pattern

Fig. 35. Measured far-field radiation patterns at 5.80 GHz for the proposed antenna

\section{Summary and outlook}

In this chapter, the antenna in RFID system is discussed, and the design of antenna is also described. The main contents include the status of the antenna in the RFID system, the design method for the antenna, the power transmission between the tag chip and the tag antenna, the tag antenna design, the scheme and design for the circular polarization, and the design of antenna for microwave band RFID tag. These researches almost cover all problems of the antenna encountering in the RFID application. The considerations and the design method are also significant for practical applications.

The development of the RFID technology for the practical applications impels the advancement of the antenna in the RFID system, and the progress of the antenna also promotes the spread of the RFID systems all over our life and society. In the future, the RFID system may require the multi-band antennas for the high reliability, or the integration of several antennas for multifunction. The unnoticed antenna is also preferred for some RFID applications. The miniaturization of the antenna is an eternal design target in 
designing the antenna, and reducing the cost of the antenna for large-scale applications is also a significant consideration in the antenna design, which will promote the development of the antenna technology. The RFID applications in special situations may initiate a new research field for designing the RFID antennas.

\section{References}

Abedin M. F. \& Ali M. (2005a). Effects of a smaller unit cell planar EBG structure on the mutual coupling of a printed dipole array, IEEE Antennas and Wireless Propagation Letters, Vol. 4, pp. 274-276.

Abedin M. F. \& Ali M.(2005b). Effects of EBG reflection phase profiles on the input impedance and bandwidth of ultra-thin directional dipoles, IEEE Transactions on Antennas and Propagation, Vol. 53, No. 11, pp. 3664-3672.

Abedin M.F. \& Ali M. (2006). A low profile dipole antenna backed by a planar EBG structure, 2006 IEEE International Workshop on Antenna Technology Small Antennas and Novel Metamaterials, pp. 13-16, March 6-8, 2006.

Aloni E. \& Kastener R. (1994). Analysis of a dual circularly polarized microstrip antenna fed by crossed slots, IEEE Transactions on Antennas and Propagation, Vol. 42, No. 8, pp. 1053-1058.

Chen, S.Y. \& Hsu, P. (2004). CPW-fed folded-slot antenna for 5.8 GHz RFID tags, Electronics Letters, Vol. 40, No. 24, pp. 1516-1517.

Dobkin D. M. \& Weigand S. M. (2005). Environmental effects on RFID tag antennas, 2005 IEEE MTT-S International Microwave Symposium Digest, pp. 135-138, June 12-17, 2005.

Fries M., Kossel M, Vahldieck R. \& Bachtold W. (2000). Aperture coupled patch antennas for an RFID system using circular polarization modulation. Proceedings of the Millennium Conference on Antennas and Propogofion, p. 358, Davos, Switzerland, April 9 - 14, 2000.

Hirvonen M., Pursula P., Jaakkola K. \& Laukkanen K.(2004). Planar inverted-F antenna for radio frequency identification, Electronics Letters, Vol. 40, No. 14, pp. 848-850.

Keskilammi M, Sydänheimo L. \& Kivikoski M. (2003). Radio frequency technology for automated manufacturing and logistics control. Part 1: Passive RFID system and the effects of antenna parameters on operational distance, The International Journal of Advanced Manufacturing Technology, Vol.21, No. 10-11, pp. 769-774.

Kim S.-J., Yu B., Lee H.-J., Park M.-J., Harackiewicz F. J., \& Lee B. (2005). RFID Tag Antenna Moutable on Metallic Plates, 2005 Asia-Pacific Microwave Conference (APMC 2005) Proceedings, Vol. 4, pp. 2666-2668.

Kossel M., Benedickter H. \& Baechtold W. (1999). Circular polarized aperture coupled patch antennas for an RFID system in the $2.4 \mathrm{GHz}$ ISM band, 1999 IEEE Radio and Wireless Conference (RAWCON 99), pp. 235-238, August 1-4, 1999.

Kossel M.A., Kung R., Benedickter H. \& Bachtold W. (1999). An active tagging system using Circular-polarization modulation, IEEE Trans. Microwave Theory and Techniques, Vol. 47, No. 12, pp. 2242-2248.

Liu, W.C. \& Hu, Z.K. (2005). Broadband CPW-fed folded-slot monopole antenna for $5.8 \mathrm{GHz}$ RFID application, Electronics Letters, Vol. 41, No. 17, pp. 5-6. 
Nikitin P. V., Rao K. V. S., Lam S. F., Pillai V., Martinez R. \& Heinrich H. (2005). Power reflection coefficient analysis for complex Impedances in RFID tag design, IEEE Transactions on Microwave Theory and Techniques, Vol.53, No.9, pp. 2721-2725.

Penttilä K., Keskilammi M., Sydänheimo L. \& Kivikoski M. (2006). Radio frequency technology for automated manufacturing and logistics control. Part 2: RFID antenna utilization in industrial applications, The International Journal of Advanced Manufacturing Technology, Vol. 31, No. 1-2, pp. 116-124.

Qing X. \& Yang N. (2004a). A folded dipole antenna for RFID, IEEE Antennas and Propagation Society International Symposium, Vol. 1, pp. 97-100, June 20-25, 2004.

Qing X. \& Yang N. (2004b). 2.45GHz circularly polarized RFID reader antenna, The Nine International Conference on Communication Systems (ICCS 2004), pp. 612-615, Sept. 68, 2004.

Rao K.V. S., Nikitin P. V. \& Lam S. F. (2005a). Impedance matching concepts in RFID transponder design, The Fourth IEEE Workshop on Automatic Identification Advanced Technologies, pp. 39-42, Oct. 17-18, 2005.

Rao K.V. S., Nikitin P. V. \& Lam S. F. (2005b). Antenna design for UHF RFID Tags: a review and a practical application, IEEE Transactions on Antennas and Propagation, Vol.53, No.12, pp. 3870-3876.

Raumonen P, Keskilammi M \& Sydanheimo L. (2004). A very low profile CP EBG antenna for RFID reader, 2004 IEEE Antennas and Propagation Society International Symposium, Vol. 4, pp. 3808-3811, June 20-25, 2004.

Sharma A.K., Singh R. \& Mittal A. (2004). Wide band dual circularly polarized aperture coupled microstrip patch antenna with bow tie shaped apertures, IEEE Antennas and Propagation Society International Symposium, June 20-25, 2004, Vol. 4, pp. 37493752.

Son H.-W., Choi G.-Y. \& Pyo C.-S.(2006). Design of wideband RFID tag antenna for metallic surfaces, Electroics Letters, Vol. 42, No. 5, pp. 263-265.

Son H.-W. \& Pyo C.-S. (2005). Design of RFID tag antenna using an inductively coupled feed, Electronics Letters, Vol. 41, No. 18, pp. 994-996.

Tikhov Y. \& Won J.H. (2004). Impedance-matching arrangement for microwave transponder operating over plurality of bent installations of antenna, Electronics Letters, Vol. 40, No. 10, pp. 574-575.

Ukkonen L., Engels D., Sydnheimo L. \& Kivikoski M. (2004). Planar wire-type inverted-F RFID tag antenna mountable on metallic objects, IEEE Antennas and Propagation Society International Symposium, Vol. 1, pp. 101-104, June 20-25, 2004.

Ukkonen L., Sydänheimo L. \& Kivikoski M. (2004). A novel tag design using inverted-F antenna for radio frequency identification of metallic objects, 2004 IEEE/Sarnoff Symposium on Advances in Wired and Wireless Communication, pp. 91-94, April 26-27, 2004.

Wang B.F. (1989). Two-port circularly polarized microstrip antennas, The Sixth International Conference on Antennas and Propagation (ICAP 89), Vol. 1, pp. 107-111, April 4-7, 1989.

Yang F. \& Rahmat-Samii Y. (2003). Reflection phase characterizations of the EBG ground plane for low profile wire antenna applications, IEEE Trans. Antennas Propagat., Vol. 51, No. 10, pp. 2691-2703. 
Zhang M.-T., Chen Y.-B., Jiao Y.-C. \& Zhang F.-S. (2006). Dual circularly polarized antenna of compact structure for RFID application, Journal of Electromagnetic Waves and Applications, Vol. 20, No. 14, pp. 1895-1902.

Zhang M.-T., Jiao Y.-C. \& Zhang F.-S. (2006). Dual-band CPW-fed folded-slot monopole antenna for RFID application, Electronics Letters, Vol. 42, No. 21, pp. 1193-1194. 


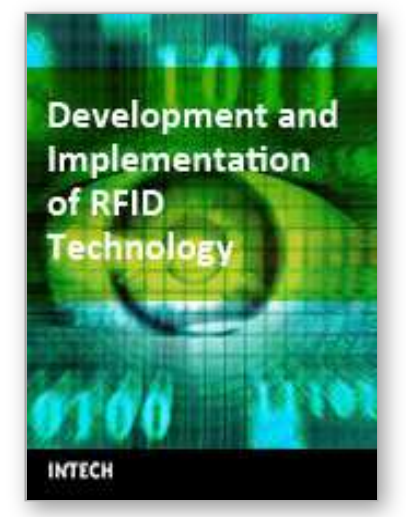

\author{
Development and Implementation of RFID Technology \\ Edited by Cristina Turcu
}

ISBN 978-3-902613-54-7

Hard cover, 450 pages

Publisher I-Tech Education and Publishing

Published online 01, January, 2009

Published in print edition January, 2009

The book generously covers a wide range of aspects and issues related to RFID systems, namely the design of RFID antennas, RFID readers and the variety of tags (e.g. UHF tags for sensing applications, surface acoustic wave RFID tags, smart RFID tags), complex RFID systems, security and privacy issues in RFID applications, as well as the selection of encryption algorithms. The book offers new insights, solutions and ideas for the design of efficient RFID architectures and applications. While not pretending to be comprehensive, its wide coverage may be appropriate not only for RFID novices but also for experienced technical professionals and RFID aficionados.

\title{
How to reference
}

In order to correctly reference this scholarly work, feel free to copy and paste the following:

Ming-Tao Zhang, Yong-Chang Jiao, Fu-Shun Zhang and Wu-Tu Wang (2009). Design of Antennas for RFID Application, Development and Implementation of RFID Technology, Cristina Turcu (Ed.), ISBN: 978-3-90261354-7, InTech, Available from:

http://www.intechopen.com/books/development_and_implementation_of_rfid_technology/design_of_antennas _for_rfid_application

\section{INTECH}

open science | open minds

\author{
InTech Europe \\ University Campus STeP Ri \\ Slavka Krautzeka 83/A \\ 51000 Rijeka, Croatia \\ Phone: +385 (51) 770447 \\ Fax: +385 (51) 686166 \\ www.intechopen.com
}

\author{
InTech China \\ Unit 405, Office Block, Hotel Equatorial Shanghai \\ No.65, Yan An Road (West), Shanghai, 200040, China \\ 中国上海市延安西路65号上海国际贵都大饭店办公楼405单元 \\ Phone: +86-21-62489820 \\ Fax: $+86-21-62489821$
}


(C) 2009 The Author(s). Licensee IntechOpen. This chapter is distributed under the terms of the Creative Commons Attribution-NonCommercialShareAlike-3.0 License, which permits use, distribution and reproduction for non-commercial purposes, provided the original is properly cited and derivative works building on this content are distributed under the same license. 